\title{
High-resolution assessment of solar energy resources over the Arabian Peninsula
}

\author{
Hari Prasad Dasari a, Srinivas Desamsetti a, Sabique Langodan a, Raju Attada a , Ravi Kumar Kunchala ${ }^{\text {a, b }}$, \\ Yesubabu Viswandhapalli ${ }^{\mathrm{c}}$, Omar Knio ${ }^{\mathrm{a}}$, Ibrahim Hoteit ${ }^{\mathrm{a}, *}$ \\ a Physical Sciences and Engineering Division, King Abdullah University of Science and Technology (KAUST), Thuwal, Saudi Arabia \\ ${ }^{\mathrm{b}}$ Centre for Atmospheric Sciences, Indian Institute of Technology (IITD), New Delhi, India \\ ${ }^{\mathrm{c}}$ National Atmospheric Research Laboratories (NARL), Department of Space (DoS), Gadanki, India
}

\section{A R T ICLE INFO}

\section{Keywords:}

Solar energy

Arabian Peninsula

WRF-solar

Global horizontal irradiance

Direct normal irradiance

Diffusive horizontal irradiance

\begin{abstract}
A B S T R A C T
This study presents a high-resolution spatial and temporal assessment of the solar energy resources over the Arabian Peninsula (AP) from 38 years (1980-2017) reanalysis data generated using an assimilative Weather Research and Forecasting Solar model. The simulations are performed based on two, two-way nested domains with $15 \mathrm{~km}$ and $5 \mathrm{~km}$ resolutions using the European Centre for Medium-Range Weather Forecasts as initial and boundary conditions and assimilating most of available observations in the region. Simulated solar energy resources, such as the Global Horizontal Irradiance (GHI), Direct Normal Irradiance (DNI), and the Diffusive Horizontal Irradiance (DHI), are first validated with daily observations collected at 46 in-situ radiometer stations over Saudi Arabia for a period of four years (2013-2016). Observed and modelled data are in good agreement with high correlation coefficients, index of agreements, and low normalized biases.

The total mean annual GHI (DNI) over the AP ranges from 6000 to $8500 \mathrm{Wh} \mathrm{m}^{-2}$ (3000 to $6500 \mathrm{Wh} \mathrm{m}^{-2}$ ) with significant seasonal variations. The diffuse fraction (the ratio of the DHI to the GHI) is high (low) over the northern (southern) AP in winter whereas it is high (low) over the central to southern (northern) AP during summer, indicating a significant modulation of the sky clearness over the region. Clouds over the northern AP in winter and the aerosol loading due to desert dust over the central and southern AP in summer are the major factors driving the variability of the DHI. The effects of dust and clouds are more pronounced in the diurnal variability of the solar radiation parameters. Our analysis of various solar radiation parameters and the aerosol properties suggest a significant potential for solar energy harvesting in the AP. In particular, the southeastern to northwestern Saudi Arabia are identified as the most suitable areas to exploit solar energy with a minimum cloud coverage over the region.
\end{abstract}

\section{Introduction}

Increasing concerns over the environment pollution resulting from the conventional energy sources such as fossil fuels has accelerated the quest for alternative energy resources. To minimize the consequences of global warming, scientific and industrial communities are extensively working on developing advanced technologies to harvest renew- able energy [1-3]. The International Energy Agency (IEA) reported that on a global basis, due to the falling costs and rapid expansion of emerging technologies, renewable energy will be the largest source of electricity in the next decade [4]. The report also pointed that the renewable global power capacity will exceed $700 \mathrm{GW}$ (GW) by 2020, and will account for two-thirds of the net power additions. Most renewable energy comes either directly or indirectly from the sun; among these,

Abbreviations: MENA, Middle East and North Africa; AP, Arabian Peninsula; KSA, Kingdom of Saudi Arabia; GHI, Global Horizontal Irradiance; DNI, Direct Normal Irradiance; DHI, Dif-

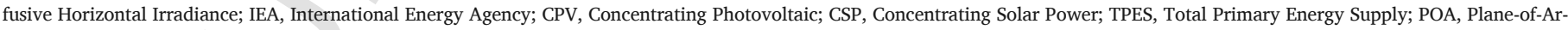

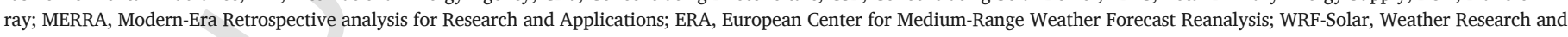

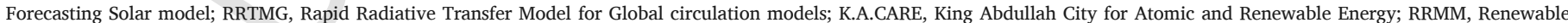

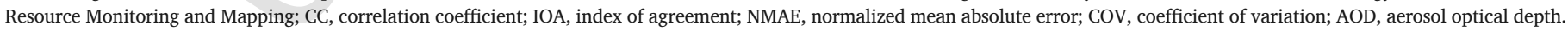

* Corresponding author at: Physical Science and Engineering Division, King Abdullah University of Science and Technology (KAUST), Thuwal 23955-6900, Saudi Arabia.

Email address: ibrahim.hoteit@kaust.edu.sa (I. Hoteit) 

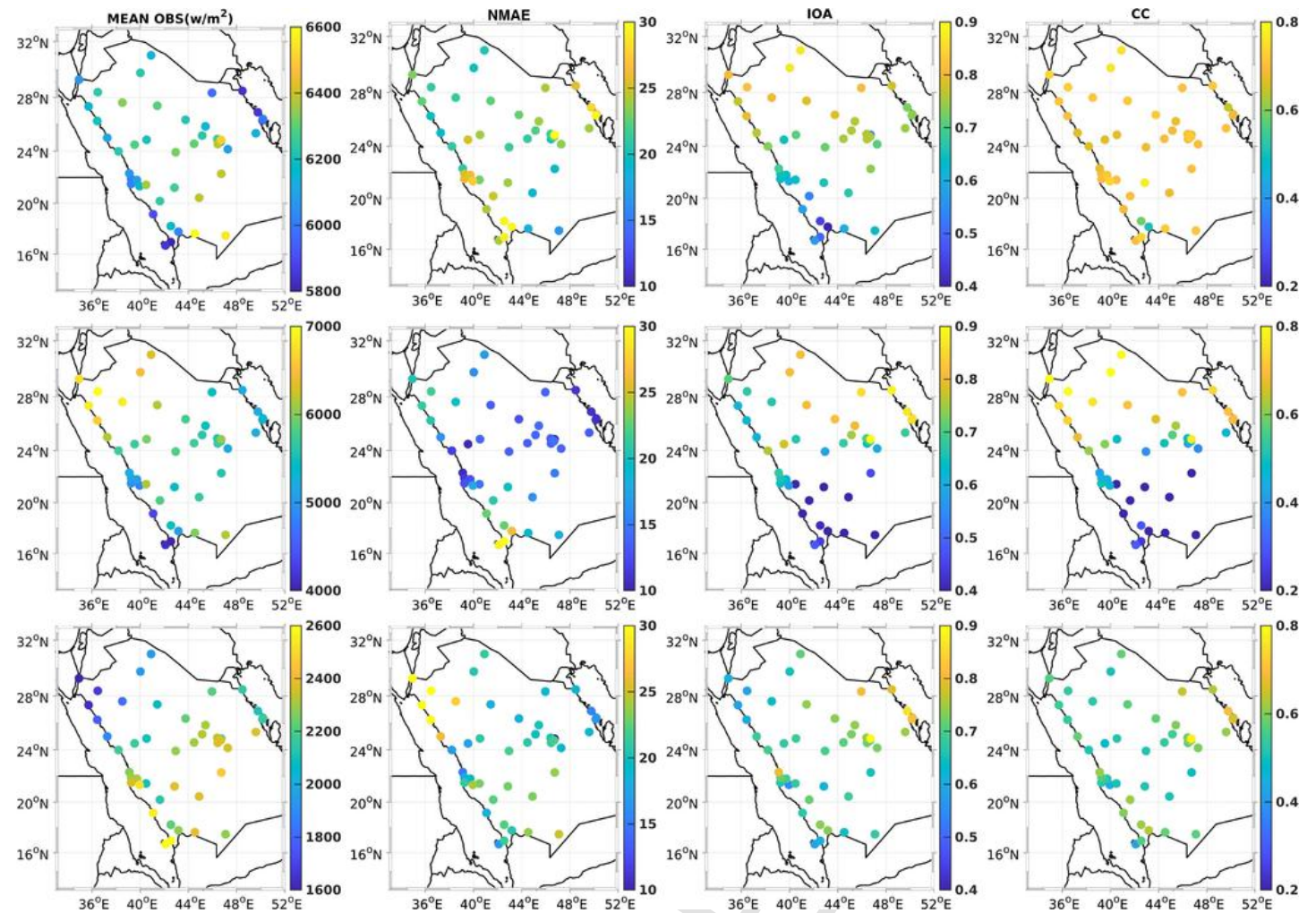

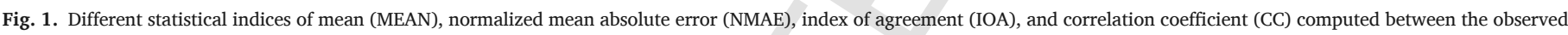
and model produced GHI (top), DNI (middle), and DHI (bottom).

solar energy is considered to be the most promising source of energy, both in terms of harvesting and reliability [5].

The development of large-scale commercial Photovoltaic (PV) and Concentrating Solar Power (CSP) establishments over different regions of the world and their economic benefits have been reported in many previous studies [e.g.,6-14]. Yang et al. [15] reported that the commercial CSP plant operations are now only available in the United States of America and Spain, producing about $4079 \mathrm{MW}$, is more than $80 \%$ of the global capacity in 2016. They also emphasized the plans of South Africa and Morocco to establish massive CSP plants by 2022 to respectively produce about $3.3 \mathrm{GW}$ and $2 \mathrm{GW}$, and the plan of Saudi Arabia to install a $25 \mathrm{GW}$ mega CSP by 2040 [15].

The rapid economic growth in the Middle East and North Africa (MENA), in particular in the Arab Gulf countries, has resulted in an increase in the regional annual Total Primary Energy Supply (TPES) by $14.9 \%$ to 800 million Mtoe (million tons of oil equivalent) in 2010 compared to 2007 [16]. The global electricity demand has been globally increasing by about $3.8 \%$ on average whereas the increase is much larger in the Middle East countries, with 7.8\% annual increase during the 1990-2014 period, meaning that the generation capacity has to be doubled every decade in this region [4]. The surging interest in renewable energy in the region calls for a better understanding of the spatial and temporal characteristics of the available solar resources in the region. This study aims to bridge the knowledge gap about the assessment of solar energy potentials in the Arabian Peninsula using state-of-the-art numerical models and available observations.

The investments in solar energy were estimated at about 5 billion USD in the Arabian Peninsula (AP) in 2015 [17], rapidly expanding in recent years to make the AP region an important market for solar energy harvesting. From 2013 onwards, several major solar PV and CSP plants were commissioned in the region, mainly in Saudi Arabia, Kuwait, and the United Arab Emirates [18]. The Kingdom of Saudi Arabia itself generates nearly $7 \mathrm{MW}$ of solar energy [1]. Along with the global network, the Saudi Renewable Resource Monitoring and Mapping Solar Measurement Network [19] supports the enhancement of the solar generating capacity in the Kingdom through observation networks and assessments. However, solar energy production highly depends on the meteorological conditions that control the solar radiation. A lack of high-resolution information has so far hindered a detailed assessment of solar energy characterization over the AP.

To assess solar energy resources, it is necessary to investigate the role of different solar radiation components at various temporal and spatial scales $[19,20]$. Global horizontal irradiance (GHI), direct normal irradiance (DNI), and diffusive horizontal irradiance (DHI) are considered as the major components needed for solar energy assessments. For instance, the essential solar resource DNI measured as a $5^{\circ}$ field view across the solar disk on a surface oriented normal to the sun's position in the sky is of particular interest for CSP and Concentrating PV (CPV) systems. DHI corresponds to the scattered solar radiation that is generally lower under clear sky conditions and is an important information for estimating the Plane-of-Array (POA) irradiance, the automation of data quality assessments, and design applications. GHI is the geometric sum of the DNI and DHI components available on a horizontal surface, which can be used alone, or in conjunction with the DNI, DHI, and albedo (reflected ground irradiance) to estimate the solar radiation on tilted flat plate collectors. The ratio of the DHI to the GHI is the diffuse fraction at different time scales that is indicative of increased cloud cover and/or higher aerosol loading during the averaging period [21], used by stakeholders to select installations based on the clearest sites.

Several studies analyzed the available global atmospheric reanalyses to assess the renewable energy resources over different regions, e.g., wind and solar energy resource over China [22] and Australian continent [23] using Modern-Era Retrospective analysis for Research and Applications (MERRA, [24]) data available at $0.5^{\circ}$ horizontal resolution, the solar energy resources over European region using European 

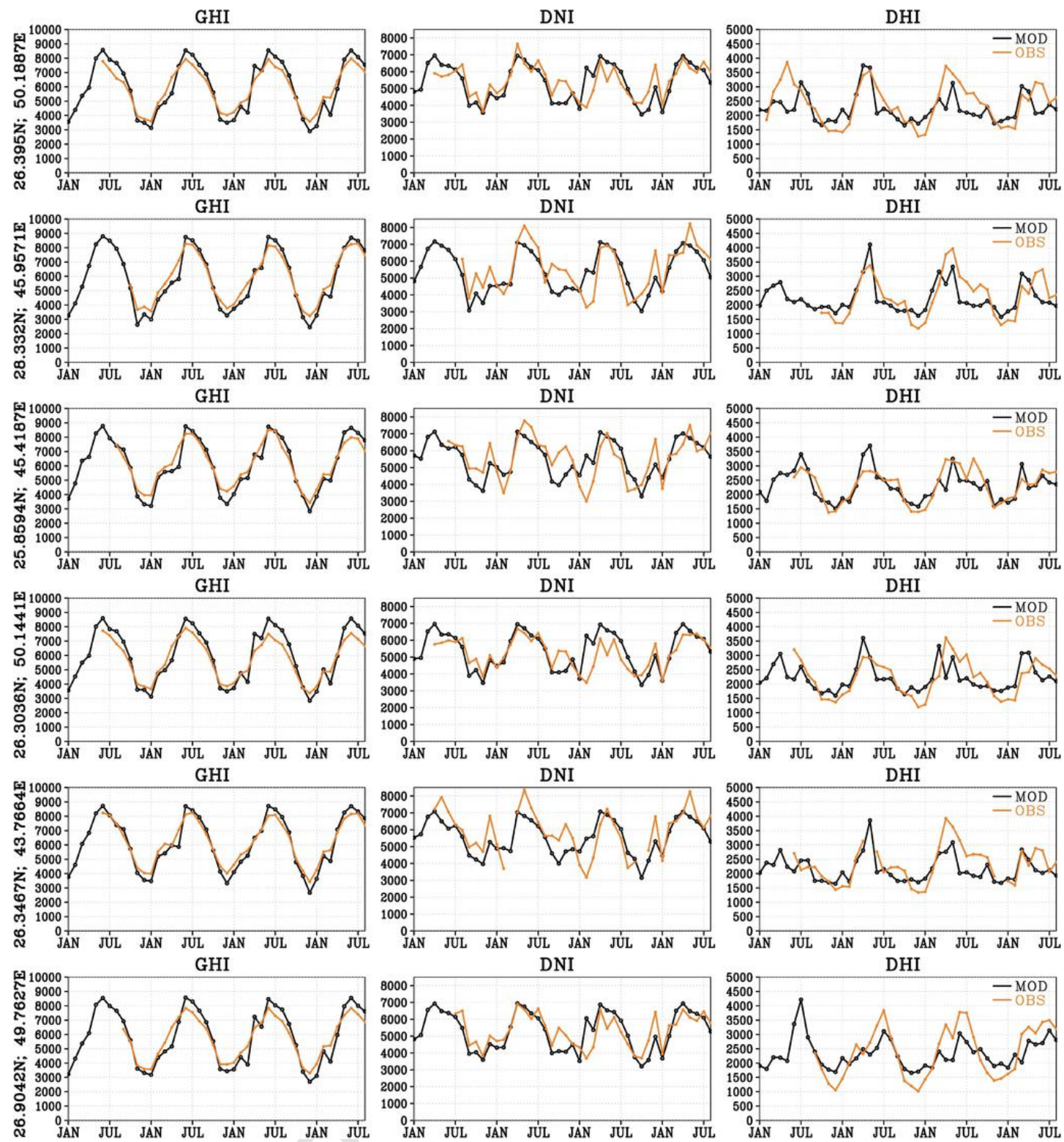

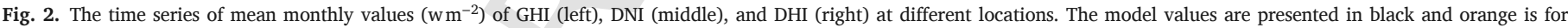

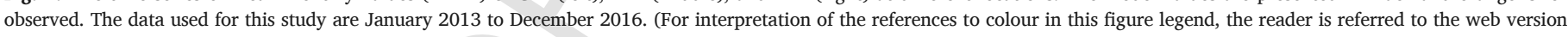
of this article.)

Center for Medium-Range Weather Forecast (ECMWF) Reanalysis (ERA) available at $75 \mathrm{~km}$ resolution [25-27]. However, the surface irradiance from the reanalysis generally exhibits a bias compared to the satellite $[28,29]$ and ground based observations $[25,30]$ and could be only used for filling the data gaps in observed times series [25], or for gross estimations of solar irradiance under clear-sky conditions [31]. Recently, Ramirez and Vindel [32] discussed the limitations of freely available global reanalyses, often available at spatial resolutions ranging between $0.5^{\circ} \times 0.5^{\circ}$ and $2.5^{\circ} \times 2.5^{\circ}$, for solar resources assessment. They strongly suggested using mesoscale models, such as WRF or MM5, to dynamically downscale the global fields to generate high resolution data over the region of interest. Jahani and Mohammadi [33] discussed the merits and shortcomings of different solar radiation estimation methods, by grouping them in to three categories: empirical relationships, artificial intelligence, and dynamical modelling, and also emphasized the importance of high-resolution datasets for accurate assessment of the solar radiation parameters.
High resolution regional models have the capacity to better describe the clouds associated with mesoscale processes, which have important impact on the solar irradiance. Recently, Urraca et al. [34] and Frank et al. [35] investigated the quality of the radiation parameters derived from the European high-resolution regional reanalysis COSMO-REA6 [36] available at a horizontal resolution of $6 \mathrm{~km}$ over a 20 years period and concluded that the high-resolution regional dataset clearly outperforms other global reanalyses. Few other studies also used the WRF model to simulate high-resolution radiation parameters over different regions over shorter duration (See for example: Chen et al. [37] for China; Lara Fanego et al. [38] for Spain; Tiriolo et al. [39] and Avolio et al. [40] for southern Europe; Kim et al. [41] for South Korea., etc.). However, all these regional modeling efforts analyzed only GHI and clearness index, and did not consider the radiation effect from aerosols in the cloud characteristics. WRF-Solar ([42], see Section 2 for details) was developed to fulfill the specific needs of the solar energy industry, by accounting for the interactions of the aerosols with 

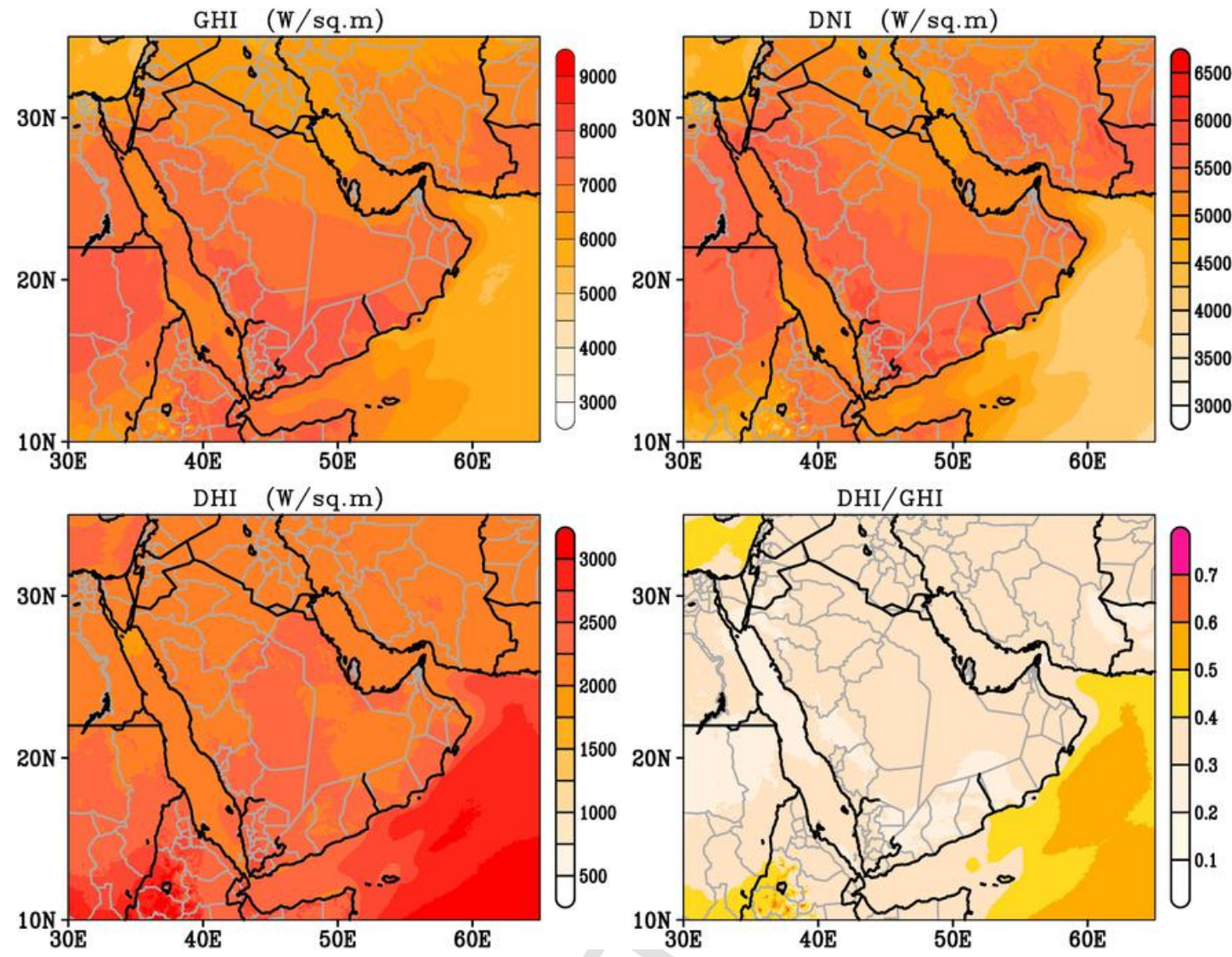

Fig. 3. Climatological (38years, 1980-2017) means $\left(\mathrm{w} \mathrm{m}^{-2}\right)$ of model GHI, DNI, DHI and the diffuse fraction (DHI/GHI) computed from the annual means.
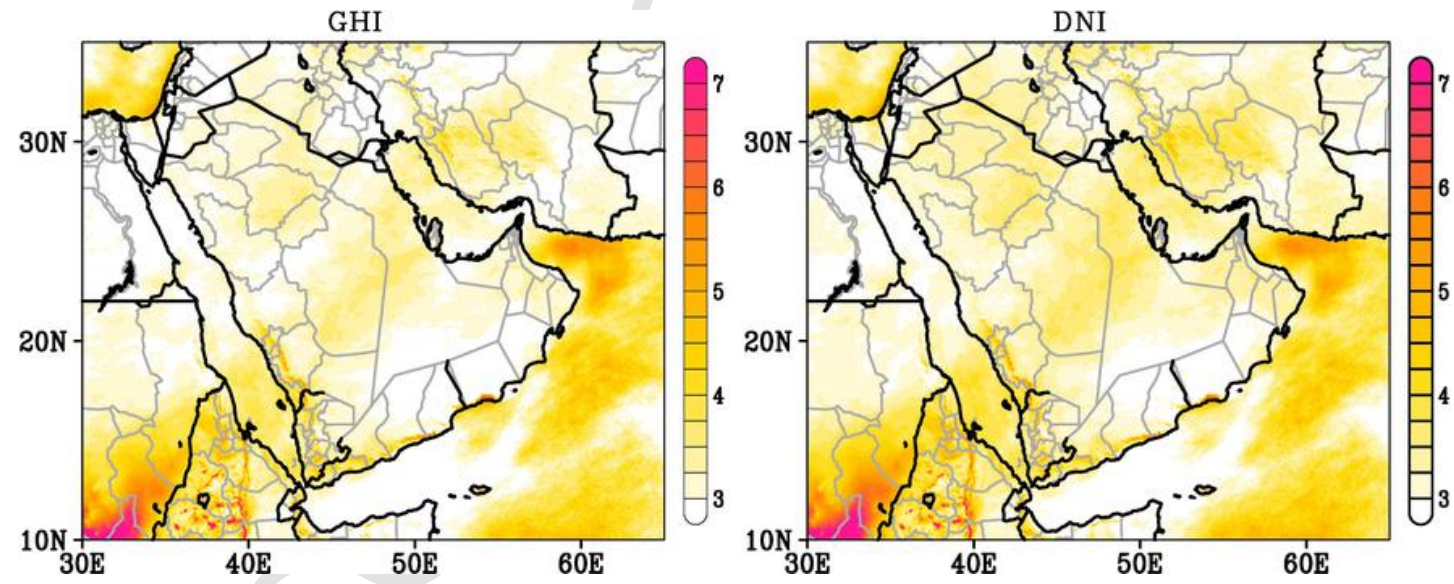

Fig. 4. The mean covariance (\%) of GHI and DNI for the annual means of model GHI and DNI for the period 1980-2017.

the cloud characteristics that modulate the evolution of the clouds and radiative properties.

Only few studies assessed solar energy resources over the AP region, based on the available observed radiation parameters [1,19,43-45]. However, a complete high-resolution characterization of the solar energy resources is still lacking for the region. This work presents the first attempt to characterize the solar energy potential over the AP based on a long-term high-resolution assimilated dataset of the region along with available observations. We used the state-of-the-art assimilative Weather Research and Forecasting Solar (WRF-Solar) model that fully accommodates for the aerosol and cloud effects on the radiation parameters and validated its outputs with the observed radiation parameters. This study uses modeling and observations to fill the knowledge gap in the characterization of solar energy potential over the AP in order to support the ongoing efforts for establishing renewable energy capabilities in the region.

The study is conducted through the following three steps:

1. We employed the state-of-the-art assimilative WRF-Solar model at $5 \mathrm{~km}$-horizontal resolution to reconstruct at best the regional solar radiation parameters over the period 1980-2017.

2. The long-term model outputs were then validated against observed radiation parameters.

3. The validated model outputs were then analyzed to explore the variability of the different solar parameters and clearness indices at different time scales in the AP. 

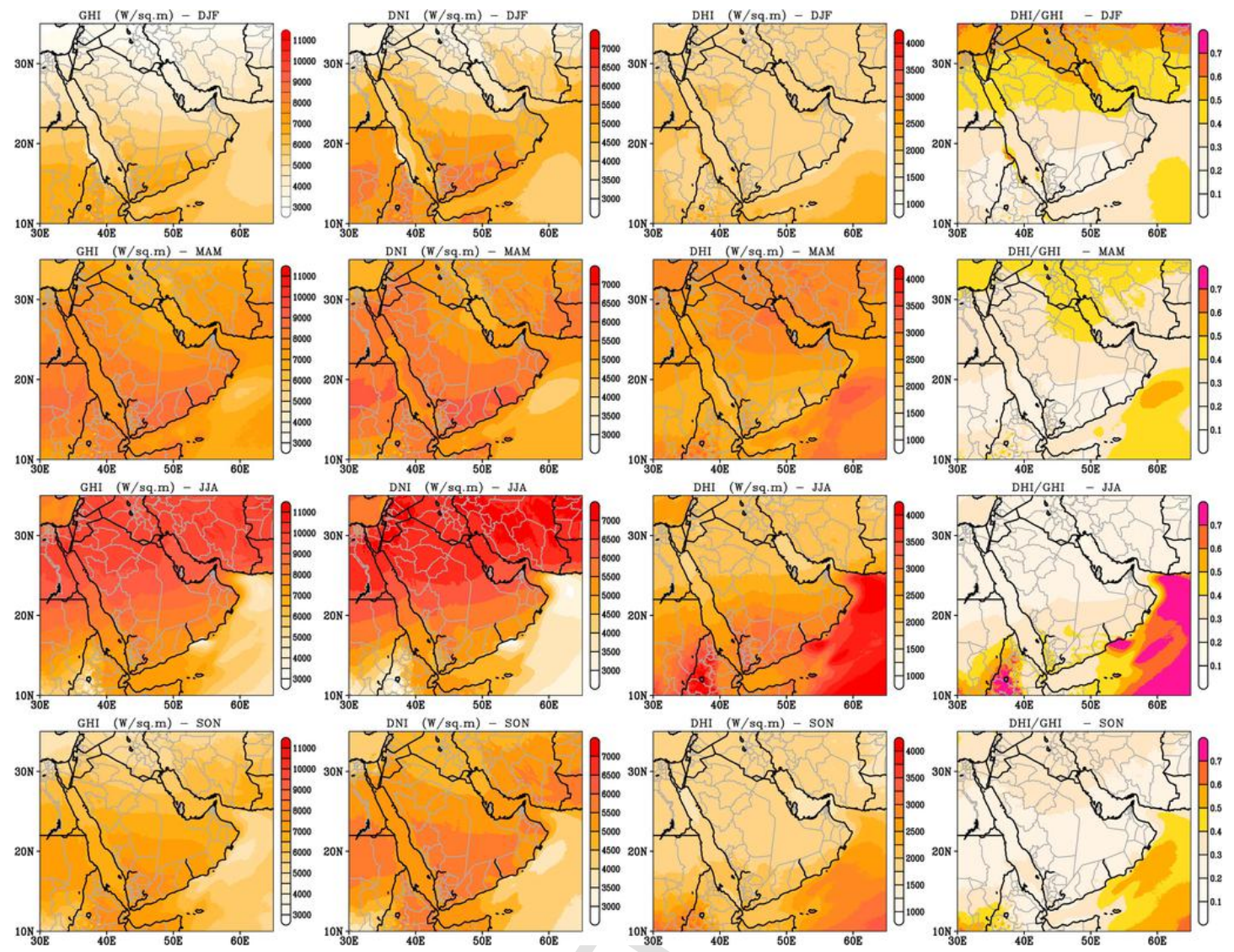

Fig. 5. Climatological (38years, 1980-2017) seasonal means $\left(\mathrm{w} \mathrm{m}^{-2}\right)$ of model GHI, DNI, DHI and the diffuse ratio (DHI/GHI).

Our analysis reveals the suitable regions for planning and designing solar energy harvesting facilities in the AP region. The remainder of the paper is organized as follows. Section 2 describes the WRF-Solar model and the observational datasets. Section 3 presents validation of the model outputs against available observations. The variability of different solar parameters at different time scales in the AP are discussed in Section 4. A discussion of the role of dust and clouds in the variability of solar resources is given in Section 5. Finally, Section 6 presents the summary and conclusions of the study.

\section{Data and methodology}

\subsection{WRF-solar system}

The acquisition of accurate solar radiance data is key for generating complete solar energy resource assessments in a region. However, solar radiation information is always limited due to sparse measurements, and this is particularly true for the AP region [19]. Modelling is considered as a viable alternative approach to derive spatially reliable homogeneous data over a specific region, particularly when driven by available observations. The integration of ground-based data with high-resolution models has been shown to provide a comprehensive and accurate characterization (on the order of $\pm 4 \%$ for annual GHI and $\pm 7 \%$ to $8 \%$ for annual DNI, globally) of the solar resources [46-48].

We employed the Weather Research and Forecast (WRF)-Solar [42] system, an explicit augmentation of the advanced WRF model [49], developed by the National Centers for Environmental Prediction (NCEP) exclusively for solar energy applications. This model focuses on the representation of cloud-aerosol-radiation systems that are important for solar energy prediction. The model computes the GHI, DNI, and the di- rect normal diffusion at every model time step by accounting for the feedback processes among the aerosols, solar irradiance, and clouds.

The main advantages of using WRF-Solar are [42,50]:

1. The solar-tracking algorithm is included to account for deviations associated with the eccentricity of the Earth's orbit and obliquity.

2. The GHI, DNI, and DHI components are computed at every time step using the radiation parameterization [51].

3. Sophisticated parameterizations are implemented to provide the surface irradiance by avoiding the computation of the three-dimensional heating rates [52].

4. A new parameterization is implemented for the absorption and scattering of the radiation due to aerosols by allowing for high-spatiotemporal variability $[20]$.

5. The augmentation accounts for the interactions of the aerosols with the cloud characteristics (aerosol indirect effects) that modulate the evolution of the clouds and radiative properties [53].

6. The feedbacks from the sub-grid scale clouds on the shortwave irradiance is implemented via the shallow cumulus parameterization $[54,55]$.

In this study, the Rapid Radiative Transfer Model for Global circulation models (RRTMG) shortwave scheme [56] was used to compute the surface irradiance components. The cloud-aerosol feedbacks are represented through the Thompson microphysics $[53,57]$. The combination of the RRTMG (both shortwave and longwave) radiation scheme and the Thompson microphysics scheme [57] incorporates the primary and secondary aerosol indirect effects $[58,59]$, which then provides the DNI estimate. The technical details of the WRF-Solar model and its evaluation for the simulation of the GHI, DHI, and DNI using different aerosol sources are reported in Ruiz-Arias et al. [20,60,61]. 

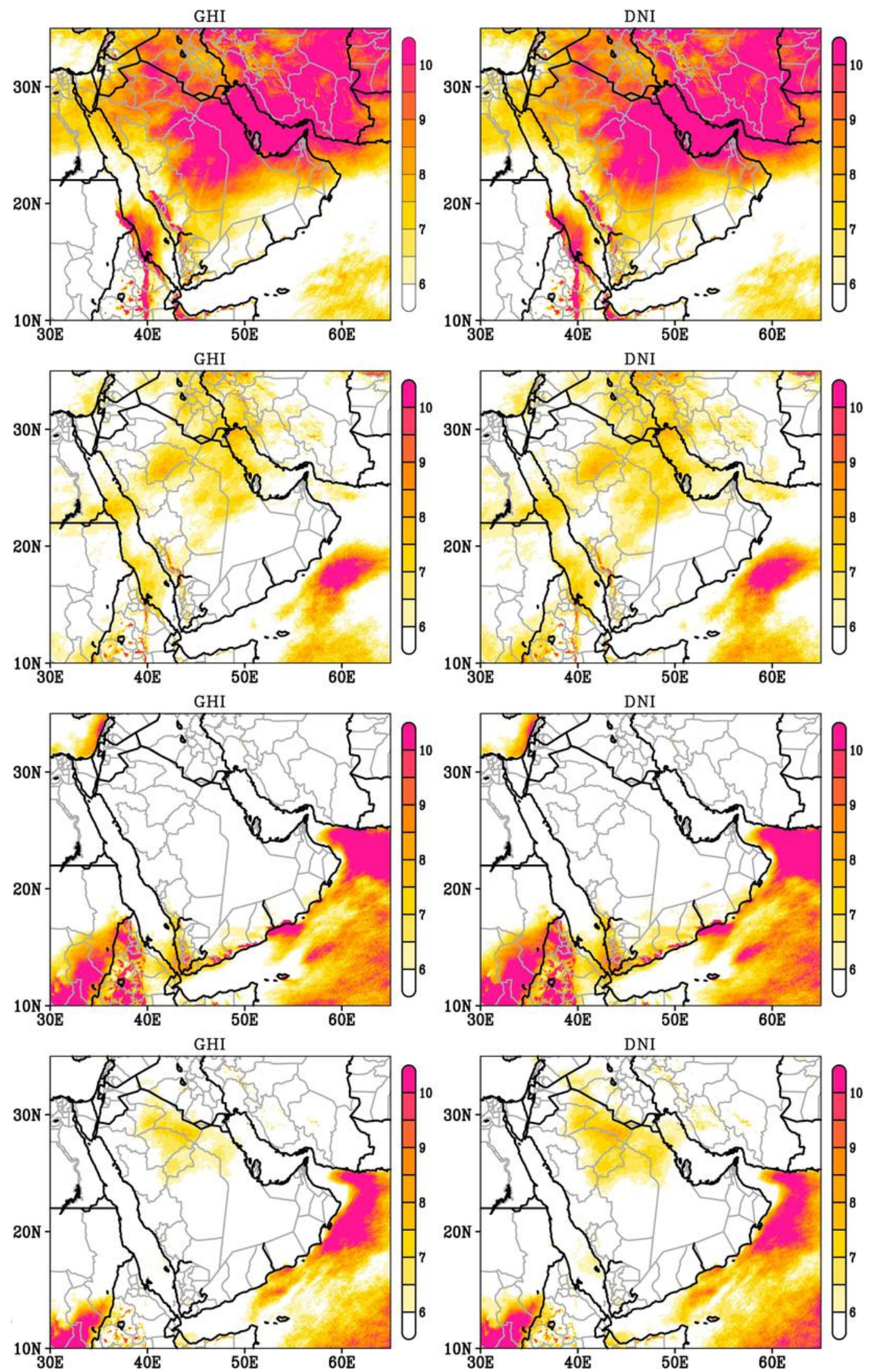

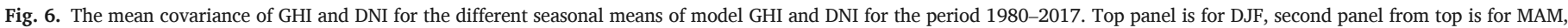
third panel from top is for JJA and bottom panel is for SON. Left column is for GHI and right column is for DNI. 

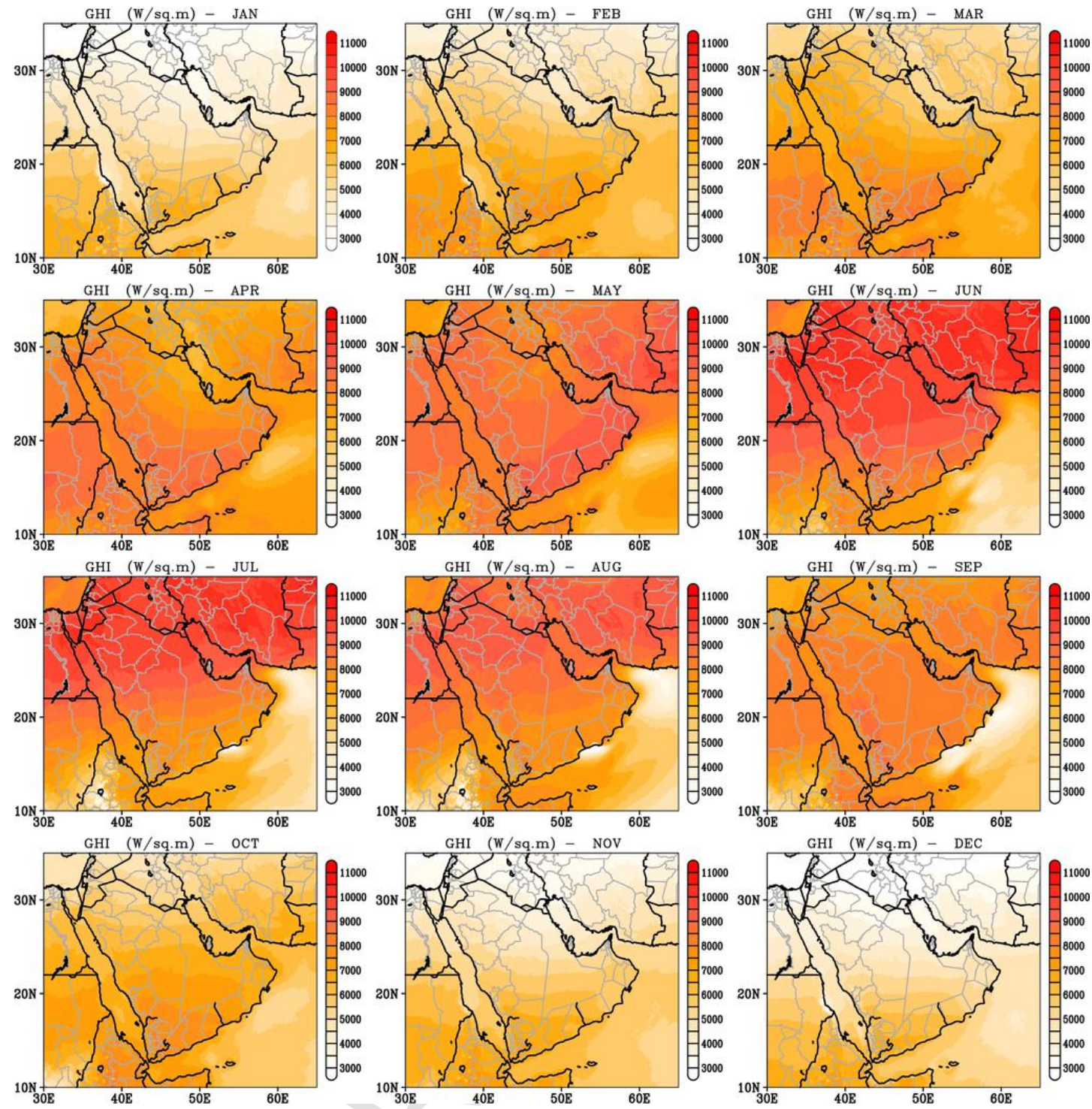

Fig. 7. Climatological (38years, 1980-2017) mean of monthly means ( $\mathrm{w} \mathrm{m}^{-2}$ ) of model GHI.

In our study, the WRF-Solar model was implemented with two, two-way nested domains with 15 and $5 \mathrm{~km}$ horizontal resolutions and 51 vertical levels. This telescopic approach of two or more domains is the standard method for dynamical downscaling, being important to avoid dynamical "shocks" that could result from direct downscaling of the $75 \mathrm{~km}$ ECMWF fields to a 5-km grid (e.g., [62-66]. The impact of domain size, horizontal resolution, and different physical processes on the downscaled outputs is discussed [67]. This "nesting" approach enables to downscale coarse data in to high-resolution information over a region of interest with minimum computational requirements. ECMWF reanalysis Interim (ERA-I) data available at a $0.75^{\circ}$ horizontal resolution [68] was used as initial and boundary conditions. All available satellite and in-situ observations in the region were assimilated into WRF using the consecutive re-initialization method as described by Viswanadhapalli et al. [69] and Langodan et al. [70,71] to generate the data over a 38-year period (1980-2017). The simulations were performed over a 36-h periods, starting at 12:00 UTC each day. The first 12-h period was neglected as a spin up (time to stabilize the model) and the remaining 24-h data were combined to generate a long-term high-resolution reanalysis for the AP.

\subsection{Solar resources observations}

King Abdullah City for Atomic and Renewable Energy (K.A.CARE) deployed a Renewable Resource Monitoring and Mapping (RRMM) Solar Measurement Network to facilitate the assessment of solar resources over Saudi Arabia. This observations network is established for investigating large-scale deployments of solar energy technologies and to optimize planning and siting of solar energy power plants [19]. Different solar parameters are measured using the rotating shadow band radiometers, with the estimated uncertainties on the observed DNI and GHI in the range of $7-9 \%$ and $6-7 \%$, respectively. Full details of the instruments, data accuracy, and the maintenance of instruments were described by Zell et al. [19], who also outlined the future road plan to increase the observational network for more assessment of the solar radiation parameters and their long-term variability in the Kingdom. More recently, Alharthi et al. [72] analyzed this dataset for the year 2015, confirming the quality of the data and the relevance of the RRMM Solar Measurement Network observations for solar resources assessment over the Kingdom. Several other studies reported that the integration of such ground-based data with dynamical models may provide an ac- 

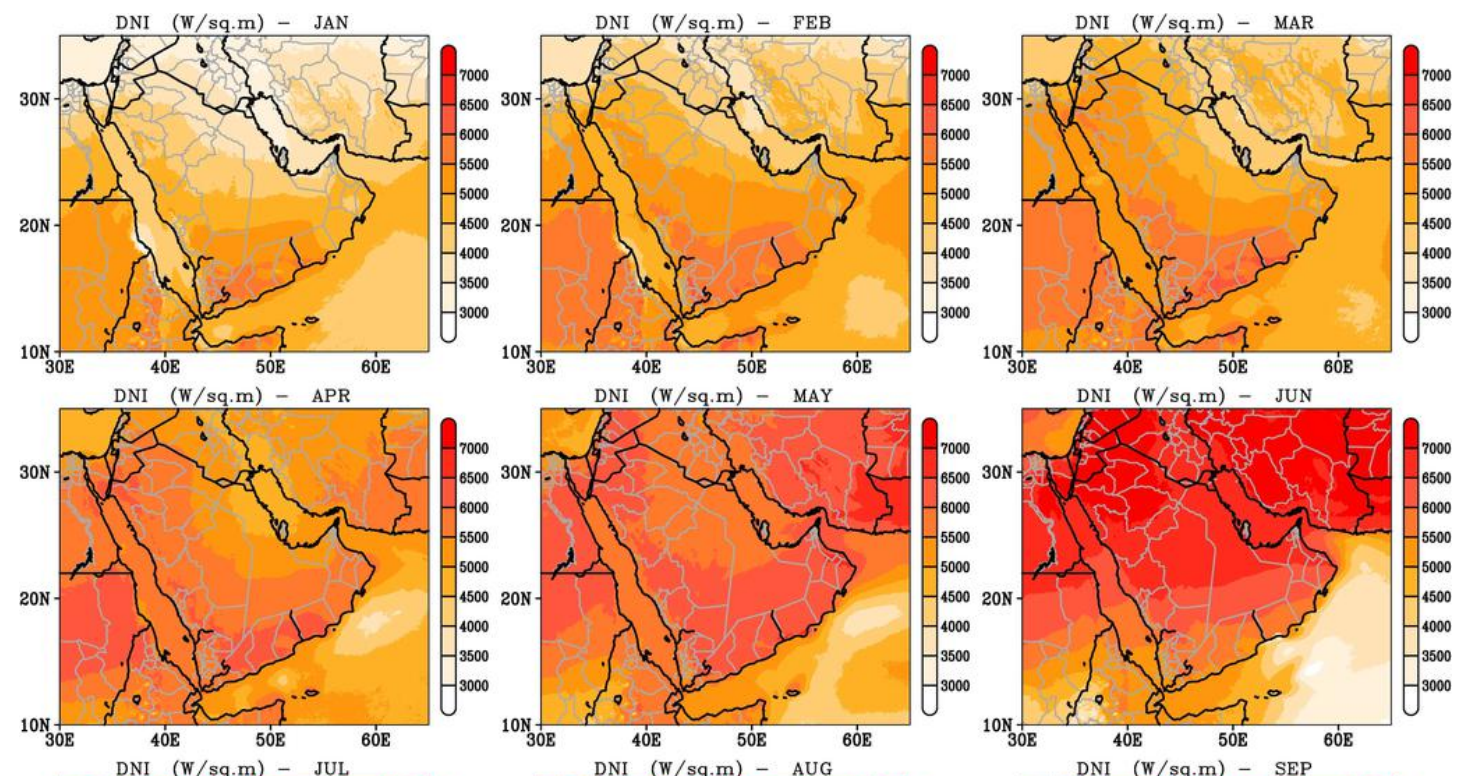

DNI (W/sq.m) - MAY
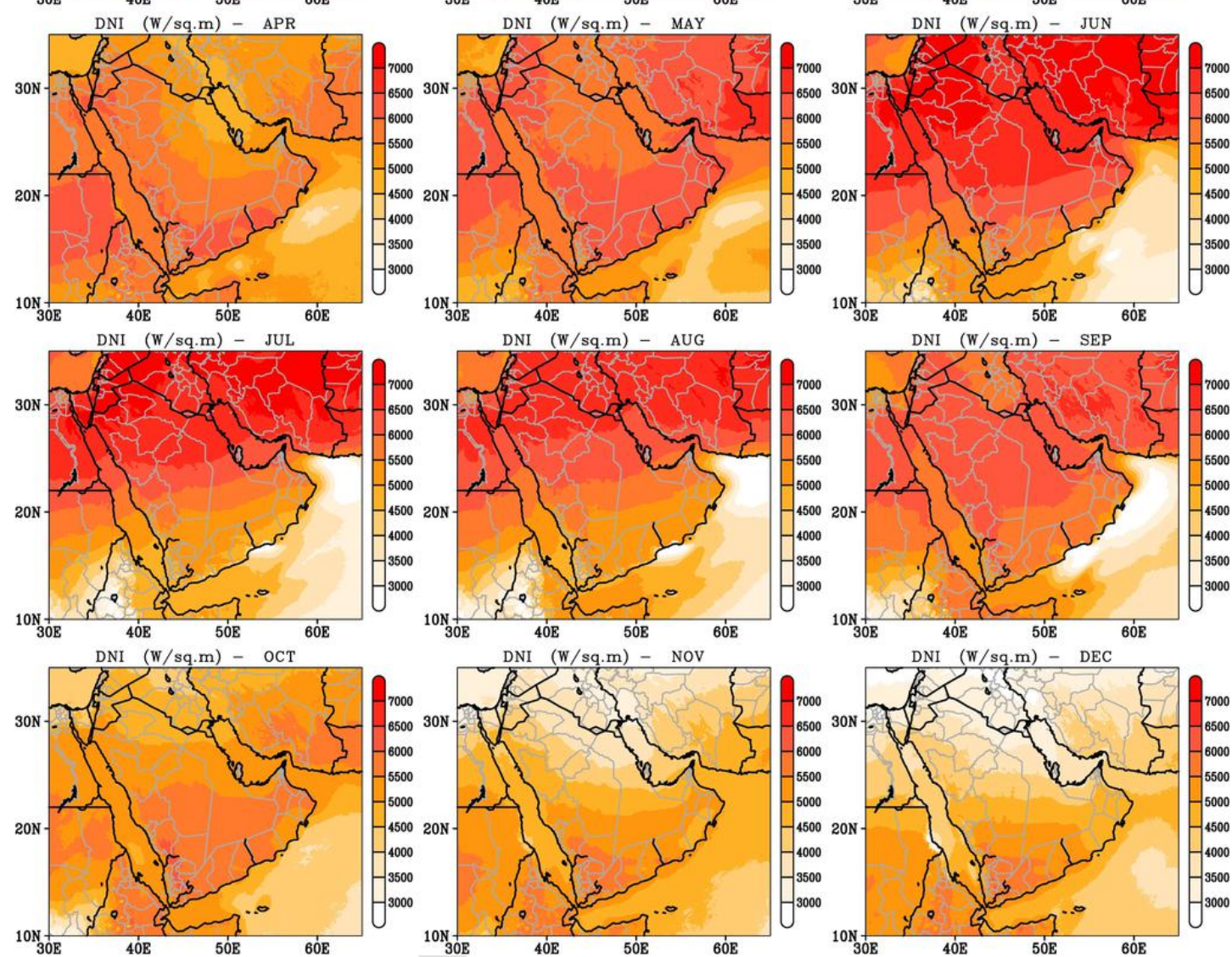

Fig. 8. Climatological (38years, 1980-2017) mean of monthly means of ( $\left.\mathrm{w} \mathrm{m}^{-2}\right)$ model DNI.

curate characterization of solar resources in the order of $\pm 4 \%$ for annual GHI and $\pm 8 \%$ for annual DNI [46-48,73].

We used the available measurements of GHI, DHI, and DNI (https:// rratlas.kacare.gov.sa/RRMMDataPortal/en/Order/Download) from 46 observation stations over the four-year period 2013-2016 to validate the solar parameters estimated from the assimilative WRF-Solar model. The monthly means of the observed parameters were used to validate the model outputs.

\section{Model validation against the radiometer observations}

We computed different statistical skill scores to evaluate the model simulations against the observations. The correlation coefficient (CC), index of agreement (IOA), and the normalized mean absolute error (NMAE) are computed based on the framework of model evaluation by Murphy and Winkler [74] as follows:

$\mathrm{CC}=\frac{\sum_{\mathrm{i}=1}^{\mathrm{n}}\left(f_{i}-\overline{\mathrm{f}}\right)\left(o_{i}-\overline{\mathrm{o}}\right)}{\sqrt{\sum_{\mathrm{i}=1}^{\mathrm{n}}\left(f_{i}-\overline{\mathrm{f}}\right)^{2}\left(o_{i}-\overline{\mathrm{o}}\right)^{2}}}$,
$\mathrm{IOA}=1.0-\frac{\sum_{\mathrm{i}=1}^{\mathrm{n}}\left(f_{i}-o_{i}\right)^{2}}{\sum_{\mathrm{i}=1}^{\mathrm{n}}\left(\left|f_{i}-\overline{\mathrm{o}}\right|+\left|o_{i}-\overline{\mathrm{o}}\right|\right)^{2}}$,

$\operatorname{MAE}=\frac{\sum_{\mathrm{i}=1}^{\mathrm{n}}\left|f_{i}-o_{i}\right|}{\mathrm{n}}$,

RANGE $=\left(o_{\max , \mathrm{i}=1, \mathrm{n}}-\mathrm{o}_{\min , \mathrm{i}=1, \mathrm{n}}\right)$,

$\mathrm{NMAE}=\frac{M A E}{R A N G E} \times 100$,

where $f_{i}$ denotes the model forecast values and $o_{i}$ the observation values.

The IOA is the degree of model prediction error [75] which ranges from 0 to 1 . A value of 1 indicates a perfect match, and 0 indicates no agreement between model and observations. The NMAE is expressed in percentages, with smaller values representing better agreement between observed and modelled values. 

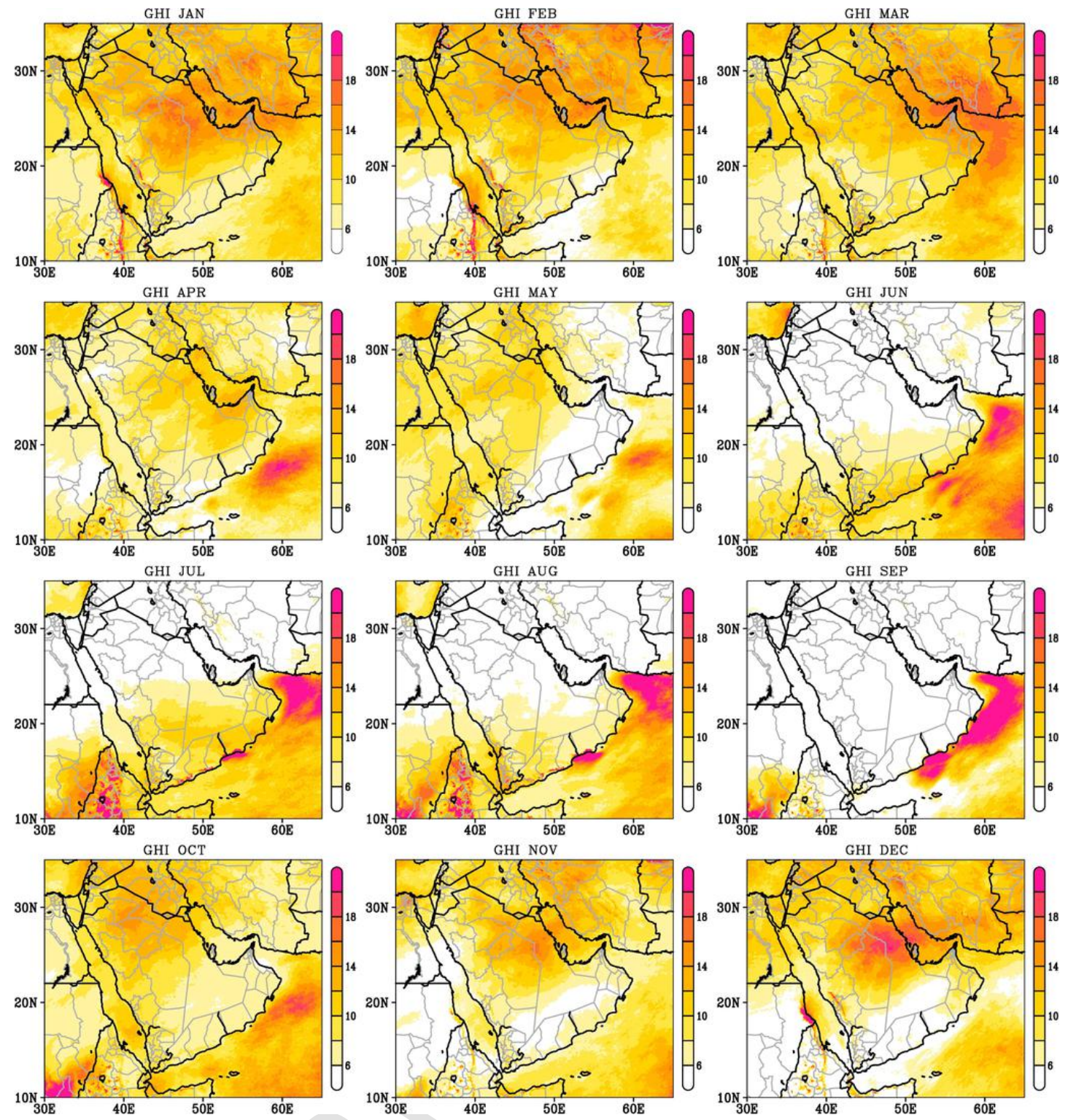

Fig. 9. The mean monthly covariance (\%) of GHI computed from the monthly means of model GHI.

The analysis results show (Fig. 1) that the model overestimates the GHI and DNI, and underestimates the DHI by about $8-10 \%$. The CC between the modelled and observed DHI and GHI was larger than 0.7 at all locations. The CC of the DNI is higher than 0.6 over most parts of Saudi Arabia, except in the southern Red Sea and adjoin regions where it reaches 0.4. The time series of the GHI, DNI, and DHI from the model and observations at selected locations representing different regions of Saudi Arabia (Fig. 2) indicate that the monthly, seasonal, and annual cycles of the different radiation parameters are well reproduced by the model.

The NMAE of the GHI is relatively higher than those of DNI and DHI. In particular, the NMAE of the DNI is about $10-15 \%$ in most of the regions, except for a small region over the southern tip of the Red Sea where the errors reach about 20\%. The NMAE of the DHI is about $20 \%$ over most of region, except over the northern Red Sea coast where it reaches $23 \%$. For GHI, higher values of NMAE of about $20-25 \%$ are observed over the southern Red Sea and western coastal regions of Saudi Arabia compared to other regions where it is less than $15 \%$. The IOA between the model and observed radiation parameters of the DNI, DHI, and GHI ranges between 0.7 and 0.9 for most of the stations, except for the southern Red Sea and adjoining regions. The strong convective activities [76] and increased dust storms [77-79] together with the complex terrain reduced the skill of the model over the southern region [69]. Overall, however, the comparisons with the observations suggest that the model simulated parameters show a reasonable accuracy to conduct the solar energy assessment study.

\section{Assessment of solar energy parameters and their variability in the AP}

We used the 38 years validated WRF-Solar simulations to assess the variability of the different radiation parameters in the AP at annual, seasonal, and monthly timescales. The annual means of the DNI, DHI, GHI, and diffuse fractions are presented in Fig. 3. The spatial distributions of GHI and DNI show similar patterns, with high values over the western and southwestern AP and low values over the eastern and northern AP. The mean annual GHI varies between 6000 and $8500 \mathrm{Whm}^{-2}$ and that of DNI between 3000 and $6500 \mathrm{Wh} \mathrm{m}^{-2}$. DHI ranged from 500 to $3000 \mathrm{Wh} \mathrm{m}^{-2}$, with high values over most of the AP and lower values over the central Red Sea and adjoining coastal re- 

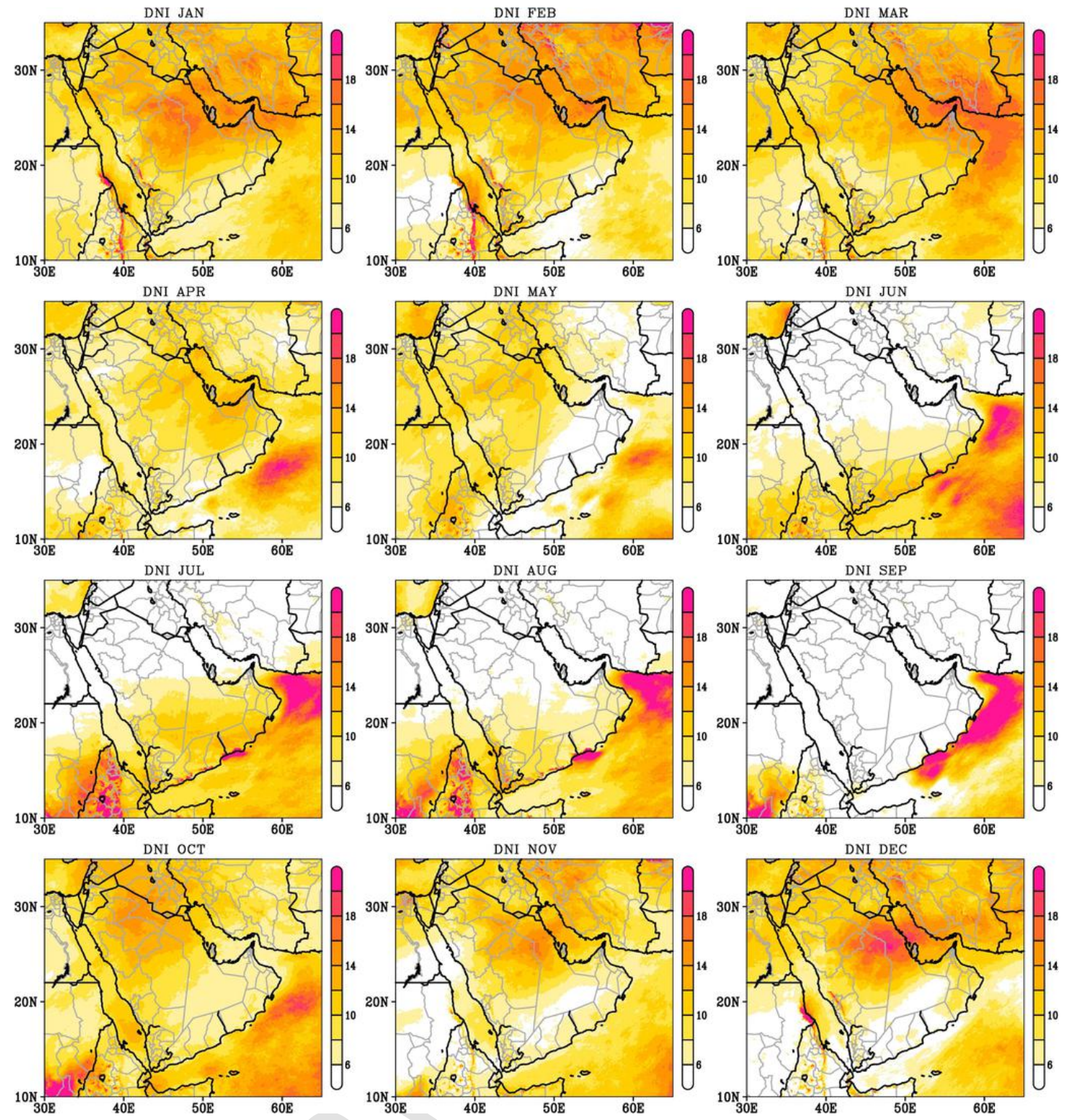

Fig. 10. The mean monthly covariance (\%) of DNI computed from the monthly means of model DNI.

gions. The regions with high (low) diffuse fractions could be related to the presence of clouds and/or dust loading [76,78-80].

To understand the extent of the interannual variability of daily mean radiation due to high aerosol loading and cloud coverage, we computed the coefficient of variation $(\mathrm{COV}=100 \times \mathrm{STD} / \mathrm{MEAN})$ at every grid point and presented the results in Fig. 4. The results indicate that the COV of the annual mean daily DNI is relatively higher than that of GHI over the entire AP. The COV of the GHI and DNI are relatively high over the southern AP, mainly due to the orography driven rainfall nature of this region $[69,76,80]$. The COV is relatively lower in most of the $\mathrm{AP}$, but higher in the regions with high DHIs, indicating higher variance over cloudy and aerosol loaded regions.

The clouds associated with the mid-latitude transient systems during winters are mainly located over the northern AP [80], whereas the southern AP is mostly dominated by the monsoon clouds [76,78-80] and dust loading [77]. These impose significant seasonal variability on the solar resources over the region. To assess the seasonal variability of the DNI, DHI, GHI and diffuse fractions, we computed the seasonal means and their COVs for each parameter and presented the results in Figs. 5 and 6. The spatial distribution of mean values of all the ana- lyzed radiation parameters over the central to northern AP suggests high values in summer and low values in winter. However, the seasonal difference in DNI values is not evident because of their low values in both seasons compared to DHI and GHI. Being the transition seasons, fall and spring exhibit intermediate values between the summer and winter GHIs and DNIs, but their distributions show strong similarity with winter.

The seasonal DHI variations indicate that the maximum varies between 2000 and $4000 \mathrm{Whm}^{-2}$ in the summer and the minimum values between 1200 and $2000 \mathrm{Whm}^{-2}$ in the winter. The maximum values in summer are noticeable over the southern AP and the minimum values in winter are confined to the eastern Red Sea region. The spring and fall patterns of the DHI closely follow the summer patterns but their magnitudes are nearly half of those in the summer $\left(\sim 1500-3000 \mathrm{Wh} \mathrm{m}^{-2}\right)$. The diffuse fraction is high over the southern regions in summer and low over the northern regions in winter. The major factors behind this contrast can be attributed to the regional cloud coverage in different seasons: (i) the Indian summer monsoon clouds over the southern AP during summer, (ii) the mid-latitude cloud 

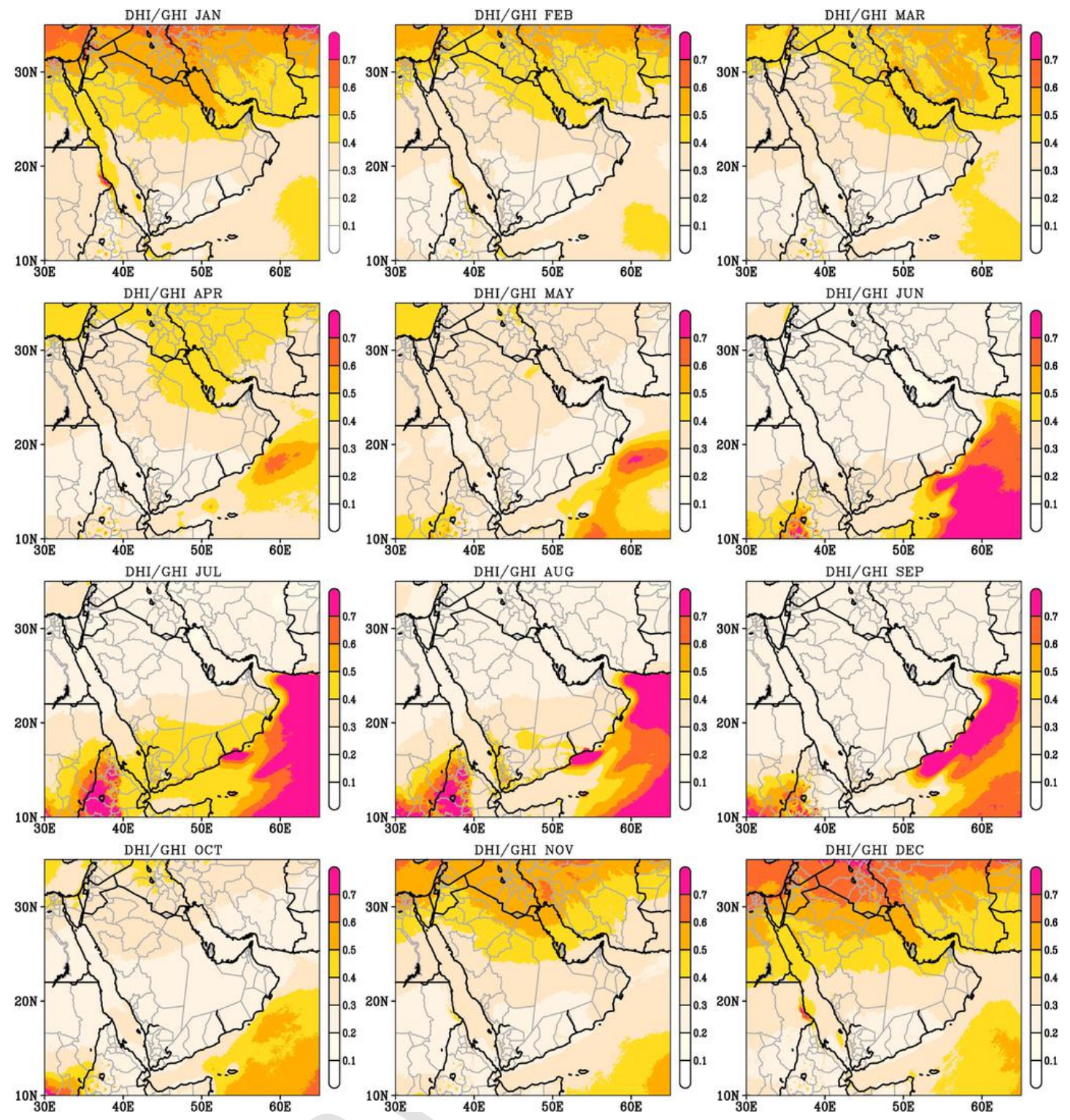

Fig. 11. The mean monthly diffuse coefficient (ration between DHI and GHI) computed from the monthly mean diffuse coefficients.

effect over the northern AP, and (iii) the north-east monsoon effect over the coastal regions of the south-western AP in winter $[69,80] . * *$

The seasonal COVs of GHI and DNI show (Fig. 6) the highest values of about $8 \%$ in winter over the eastern and north eastern AP. The fall distribution is similar to that of the summer, with lower magnitudes $(\sim 6 \%)$ due to the increased frequency of dust storms [81]. In summer, the COVs of GHI and DNI are minimal over the central to northern AP and increases to $10 \%$ over the southwestern AP regions due to the monsoon flow induced clouds. In spring, the COVs of GHI and DNI are about $8 \%$ over the monsoon flow region. Another maximum was also observed over the central Saudi Arabia, associated with the influence of the Tokar gap winds in the summer [70].

The monthly means of GHI (Fig. 7) and DNI (Fig. 8) show gradual increases from January to April, peaking to their maximum values between May and September, and then decreasing to their minimum values starting from December. According to the difference in solar insolation, the location of the maxima migrates between the north and south. The location of the maximum of the mean DHI (results not shown) starts shifting from north to south from February to November. A uniform distribution of the $\mathrm{DHI}$ is observed over the entire region during
December and January. The monthly values of the DHI are high between April and September and relatively low during the remaining months. This suggests the effects of clouds over the northern AP in winter (October to March) and the aerosol loading due to desert dust over the central and southern AP in summer (May to September) [76,77].

The COVs of GHI and DNI displayed in Figs. 9 and 10 clearly show that the northern AP exhibit higher COV of about $12 \%$ in the winter months between October and March, while the summer shows slightly lower values over the eastern AP. The COV reached up to $17 \%$ south of $15^{\circ} \mathrm{N}$ in summer, mainly due to the presence of dust and the Indian summer monsoon clouds coverage. The diffuse fraction values (Fig. 11) are significantly higher over the northern AP between November and February, start decreasing from March to April, before reaching their minimum in summer (May and August). The transition from low to high values of the diffuse fraction over the southern and northern AP exhibits an opposite behavior. The southern AP shows low diffuse fraction values during winter, start increasing from May onwards, and reach their maximum in July. 
(a) JANUARY

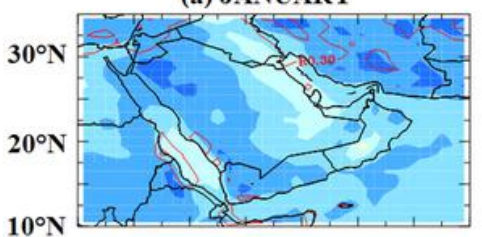

(d) APRIL

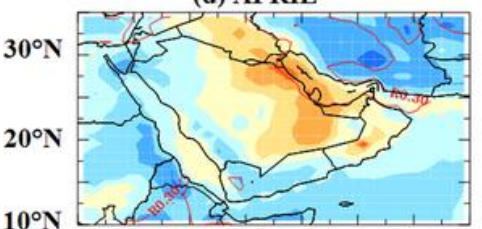

(g) JULY

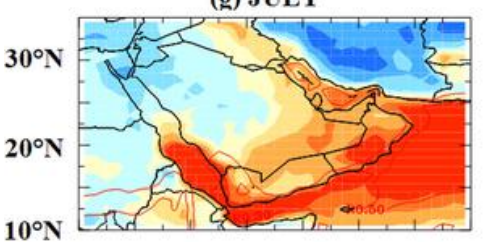

(i) OCTOBER

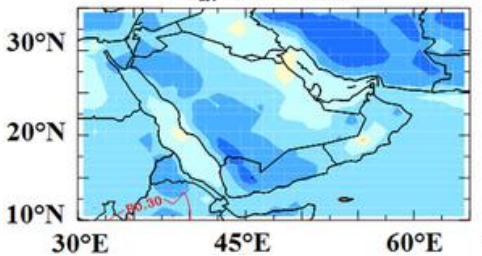

(b) FEBRUARY

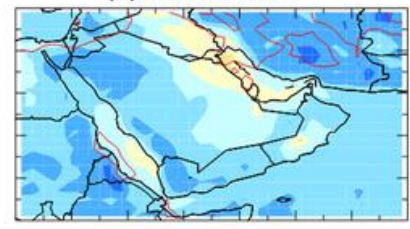

(e) MAY

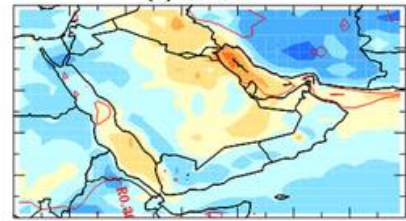

(h) AUGUST

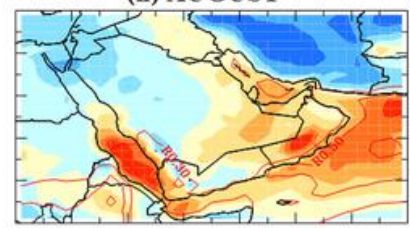

(k) NOVEMBER

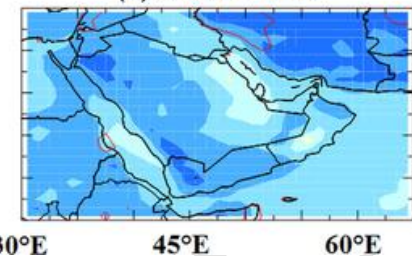

(c) MARCH

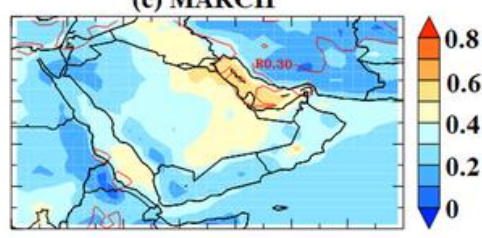

(f) JUNE

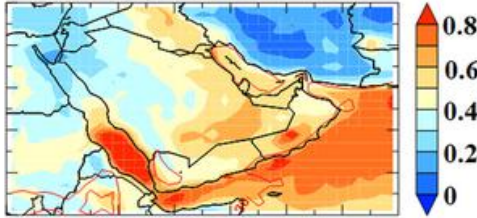

(i) SEPTEMBER

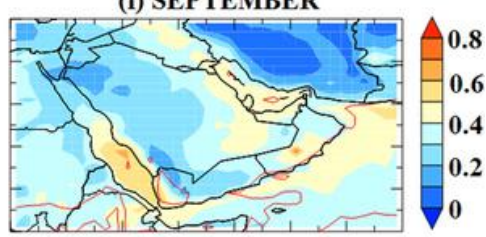

(1) DECEMBER

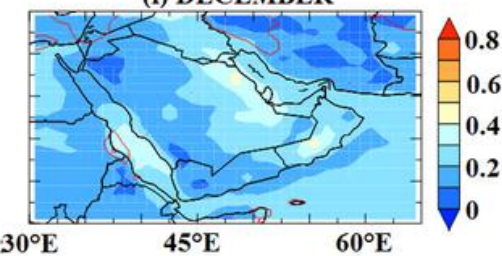

Fig. 12. Climatological monthly means of AOD and Cloud Cover (contours) from MODIS data. Monthly means are computed for the period 2003-2017.

\section{Impact of dust and clouds}

The availability of solar resources is related to the sun's irradiance and spectral content. Other external factors related to the geographical location and local conditions can however have important impact on the availability of solar energy resources [17]. Among these, dust and cloud coverage are the major variables that characterize the viability of a solar installation [42,50,82-84]. The presence of dust due to storms over the AP may therefore have a significant influence on solar energy applications. The dust emissions from these regional storms are generally triggered by large-scale atmospheric instabilities and high surface winds [85-88]. The quality of the observed solar parameters may also depend on the dust deposition and requires regular maintenance of the instruments to ensure quality data measurements [19].

To assess the impact of the dust and cloud fractions on the solar resources over the AP we analyzed the monthly variability of the aerosol optical depth (AOD) and cloud coverage over the region. The results show that the maximum values of the AOD (Fig. 12) over the southern AP mainly occur during the summer months. A clear sky with lower AODs generally prevails over the northern AP, except during summer when the dust transported by the Shamal winds act as an opaque filter for the solar radiation [77]. In contrast, the southern AP exhibits a relatively higher AOD in summer due to the aerosol loading and clouds associated with the Indian summer monsoon [76-79]. The dust over the northern AP and clouds over the southern AP play an important role in modulating the higher diffuse fractions. Similarly, in winter months over the northern AP, the higher diffuse fractions are mainly due to the clouds that are induced by the mid-latitude weather systems [80].

The spatial distributions of the AOD and cloud coverage indicate the areas of high clearness index; however, the persistence of these conditions and the diurnal variations in particular are also important factors for solar energy installations. To assess the diurnal variations of the clearness index due to the presence of clouds and dust, we considered three locations representing the northwestern $\left(\mathrm{L} 1,27.84696^{\circ} \mathrm{N}\right.$; $36.64078^{\circ} \mathrm{E}$ ), southwestern (L2, $18.11161^{\circ} \mathrm{N} ; 43.49429^{\circ} \mathrm{E}$ ), and eastern $\left(\mathrm{L} 3,25.76176^{\circ} \mathrm{N} ; 48.94594^{\circ} \mathrm{E}\right)$ regions of Saudi Arabia. These three locations were identified based on the spatial distribution of the monthly AOD and cloud coverage.

Figs. 13, 14, and 15 present for each location the boxplot for the hourly clearness index of each month with the full range of the variations (from minimum to maximum), the first quartile, the median, and the third quartile. The seasonal differences in the diurnal distribution of the clearness index are clear at all three locations. L1 shows a consistent uniform clearness index over the entire year with minimum variation, except in winter (November to February) where a higher variability is noticeable in the morning and evening hours. The clearness index exhibits substantial diurnal variability at L2 in summer (June to September) and high diurnal variability at L3 between October and March. These results indicate that the L1 location in the northwestern Red Sea is affected by the mid latitude cloud systems in winter and the L2 location in the southwestern location is affected by the higher AOD and more cloud coverage. The eastern location L3 shows higher diurnal variations during months with higher AOD and higher cloud coverage (Fig. 12), suggesting that the effects of clouds and dust at the diurnal scale are overall well represented by the WRF-Solar model.

\section{Summary and conclusions}

This study assessed the solar energy resources over the AP. We implemented an assimilative WRF-Solar model to generate a long-term (1980-2017) high-resolution $(5 \mathrm{~km})$ dataset of different irradiance 

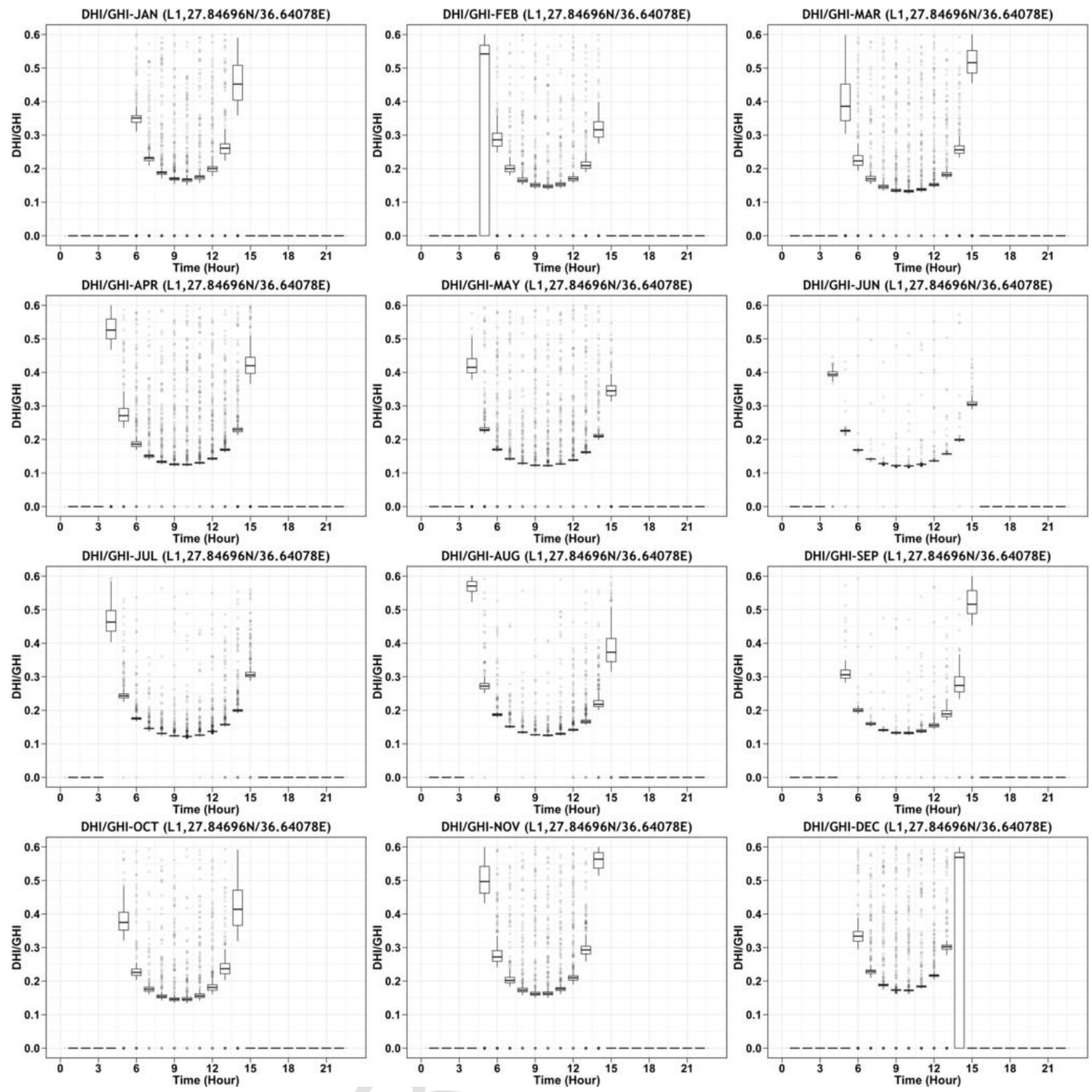

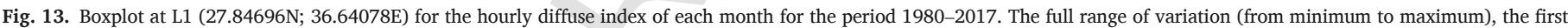
quartile, the third quartile and the median are presented.

variables, including GHI, DNI, and DHI over the AP region by downscaling ERA-interim global reanalysis data. The model simulations were validated by comparisons with solar radiation measurements from 46 radiometers distributed over Saudi Arabia. These instruments are deployed and maintained by the Renewable Resource Monitoring and Mapping (RRMM) Solar Measurement Network to support the assessment of solar resources over the Kingdom of Saudi Arabia.

The main findings of our study are:

1. The statistical scores of the comparison between our model outputs and observations (correlation coefficient is greater than 0.8 with $95 \%$ significance; the normalized bias is around $10-15 \%$, and the index of agreement is about 0.7 ) suggest that the simulated solar parameters are reasonably accurate to conduct the solar energy assessment study.

2. The annual means of the model simulated irradiances DNI, DHI, GHI, and diffuse fractions (the ratio of the DHI to GHI) were found to be high over the western and the southwestern Red Sea regions. The GHI and DNI also exhibited similar patterns of high values over the western and southwestern Red Sea and low values over the eastern and the northern AP. The annual mean of the GHI over the AP ranged from 6000 to $8500 \mathrm{Wh} \mathrm{m}^{-2}$, whereas the DNI ranged from about 3000 to $6500 \mathrm{Wh} \mathrm{m}^{-2}$.

3. The significant changes in the coefficient of variability of GHI and DNI between summer and winter indicates a strong seasonal variability in the solar resources over the AP. Moreover, the solar resources exhibited a strong sensitivity to the regional climate; for instance, the Indian summer monsoon was a factor in modulating the solar energy over the southern AP, whereas the northern part was dominated by the Mediterranean weather systems.

4. Monthly analysis of the DNI, DHI, and GHI showed a gradual increase between January and April, with the maximum occurring between May and September. The location of the maxima of the DNI and GHI migrated from the southern to the northern AP between January and September and the location of the maximum of the mean DHI moved southward between February and November. The DHI was high from April to September, suggesting the effects of clouds over the northern AP in winter (October to March) and the aerosol loading due to desert dust over the central and southern AP in summer (May to September). The percentage of the coefficient of variations for GHI and DNI were higher over the northern AP in winter between October to February and reached up to $17 \%$ south 

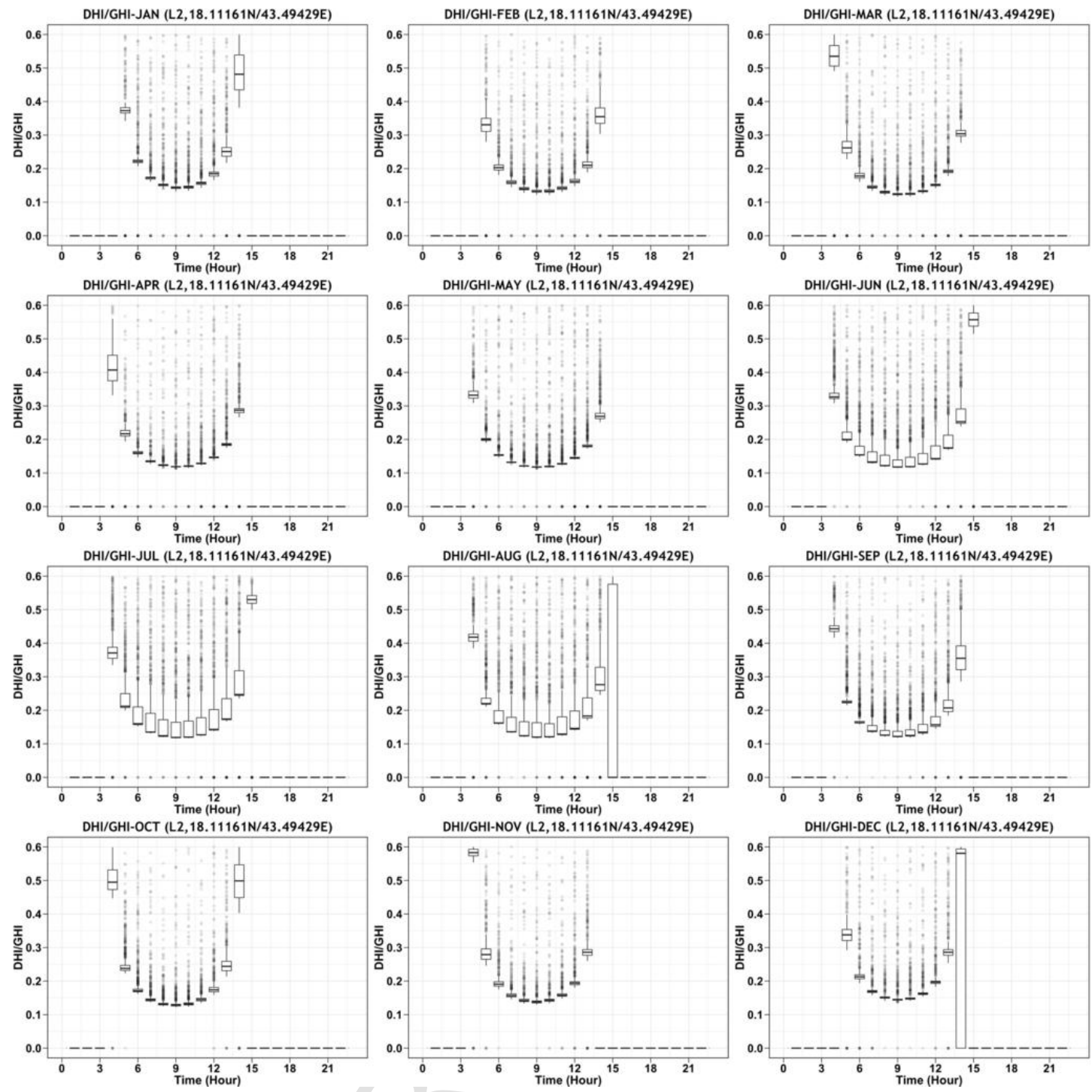

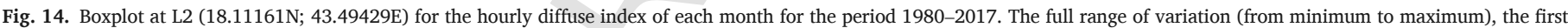
quartile, the third quartile and the median are presented.

of $15^{\circ} \mathrm{N}$ in summer, due to the transport of dust and the monsoon related clouds. The diffuse fraction was high/low over the northern/ southern AP from November to February.

5. The diurnal variation of clearness index suggests that the northwestern and eastern parts of Saudi Arabia exhibit significant diurnal variability in winter, whereas the southwestern regions show high diurnal variability in summer. Our analysis indicate that the northwestern and eastern regions are affected by the mid latitude weather systems in winter, while the southwestern region is affected by the higher AOD and cloud coverage in summer.

6. Our analysis of various solar radiation parameters and the aerosol properties outlines a general picture of solar energy potential over the AP, suggesting significant potential to support energy needs in this region. The northeastern and southwestern AP regions are respectively significantly affected by the cloud coverage and dust aerosol loading during winter and summer and are thus not viable for solar energy exploitation. Though the presence of dust causes a low diffuse index, the southeastern to northwestern regions of Saudi Arabia are more suitable for solar energy harvesting.
The generated long-term outputs of the WRF-Solar model describe reasonably well the varying solar resources conditions over the AP, and can thus help closing the information gap in the regional solar radiation resources. In addition, this dataset contains enough information to support the developments of viable solar energy capabilities in the country. The economic assessment of derivable solar power is not considered in this study and is difficult to evaluate based solely on the results presented here, as it depends on the choice of power plants and optimization of electricity system configuration in the region. The AP, in particular Kingdom of Saudi Arabia under the vision 2030, is one of the rapidly growing renewable energy markets and this study provides the essential information for researchers and policy makers for developing efficient strategies for solar energy harvesting.

This study did not consider the impact of the land disturbance, land use, and the dust/relative-humidity/air-temperature risk on the solar energy harvesting in the AP and more work is still needed in this regard to understand the role of these factors in modulating the solar power in the region. Moreover, forecasts of cloud characteristics are still an immense concern for the mesoscale models and further improvements in WRF-Solar should be achieved for more accurate DNI 

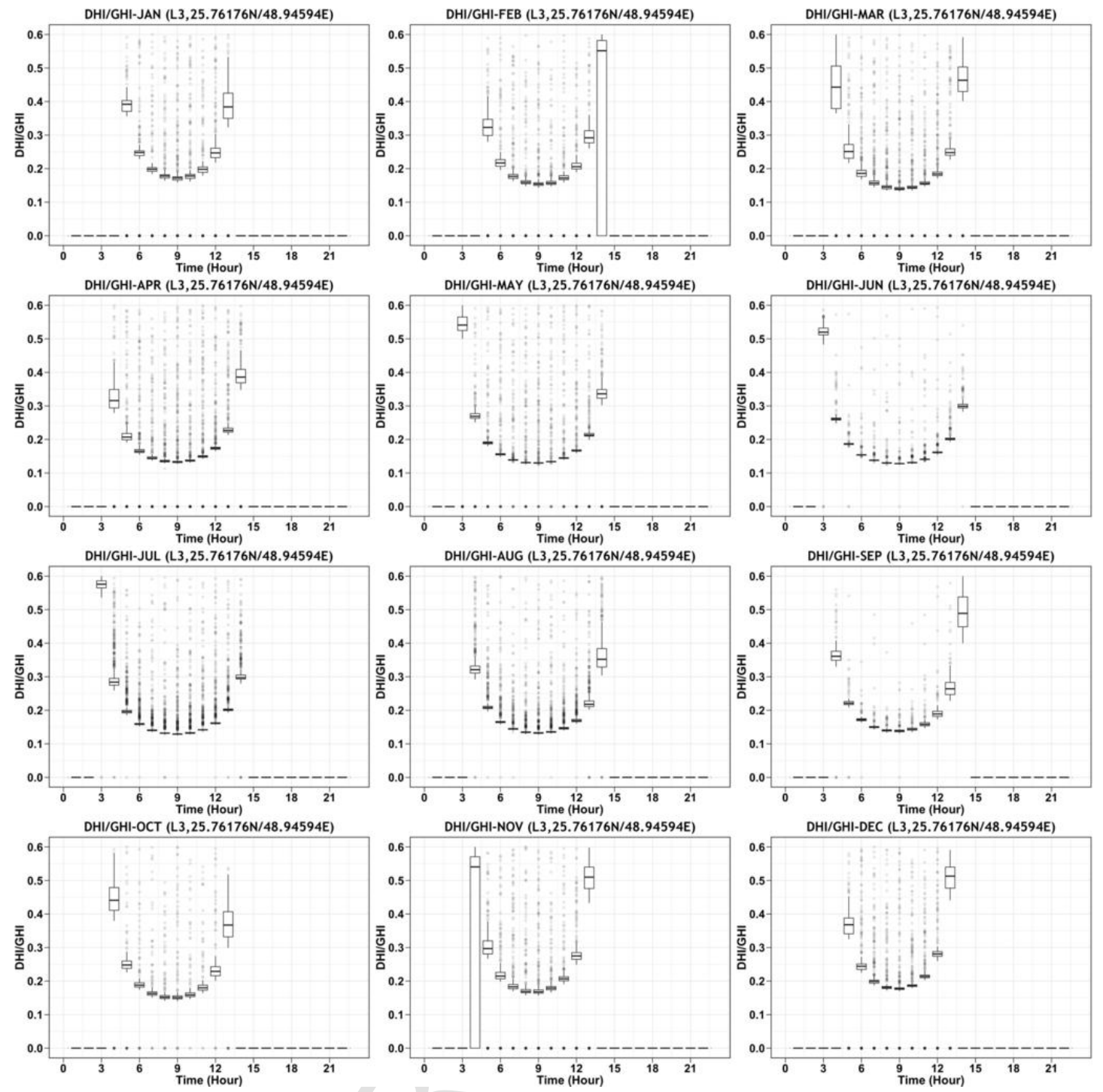

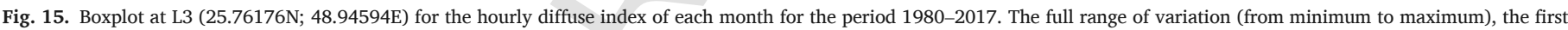
quartile, the third quartile and the median are presented.

and GHI estimates during cloudy and overcast conditions for real-time solar applications. These directions will be explored in future studies.

\section{Acknowledgments}

The study was supported by King Abdullah University of Science and Technology (KAUST) under the "Virtual Red Sea Initiative", Award Number REP/1/3268-01-01 and the Saudi ARAMCO-KAUST Marine Environmental Research Center (SAKMERC). The research made use of the Supercomputing Laboratory resources at KAUST. We thank King Abdullah City for Atomic and Renewable Energy for making the radiometer observations from the Renewable Resource Monitoring and Mapping Solar Measurement Network available online.

\section{Appendix A. Supplementary material}

Supplementary data to this article can be found online at https:// doi.org/10.1016/j.apenergy.2019.04.105.

\section{References}

[1] Bryden J, Riahi L, Zissler R. MENA Renewables Status Report: MENA 2013. United Arab Emirates, Directorate of Energy \& Climate Change, Ministry of Foreign Affairs; International Renewable Energy Agency; Renewable Energy Policy Network for the 21st Century; 2013. <http://www.ren21.net/Portals/0/documents/ activities/Regional\%20Reports/MENA_2013_lowres.pdf > [accessed on 9 May, 2018].

[2] C.B. Martinez-Anido, B. Botor, A.R. Florita, C. Draxl, S. Lu, H.F. Hamann, et al., The value of day-ahead solar power forecasting improvement, Sol Energy 129 (2016) 192-203, https://doi.org/10.1016/j.solener.2016.01.049.

[3] Haupt SE, et al. The SunCast solar power forecasting system: The results of the Public-Private-Academic Partnership to Advance Solar Power Forecasting. NCAR Tech. Note NCAR/TN-526+STR; 2016. p. 307. < https://doi.org/10.5065/ D6N58JR2 $>$.

[4] IEA/International Energy Agency. IEA World Energy Statistics and Balances; 2016. https://doi.org/10.1787/enestats-data-en.

[5] Bird L, Milligan M, Lew D. Integrating variable renewable energy: challenges and solutions. National Renewable Energy Laboratory, Technical Report NREL/ TP-6A20-60451; 2013. < https://www.nrel.gov/docs/fy13osti/60451.pdf > .

[6] S.H. Madaeni, R. Sioshansi, P. Denholm, How thermal energy storage enhances the economic viability of concentrating solar power, Proc IEEE 100 (2) (2012) 335-347.

[7] Y. Tian, C.Y. Zhao, A review of solar collectors and thermal energy storage in solar thermal applications, Appl Energy 104 (2013) 538-553. 
[8] W. Li, P. Wei, X. Zhou, A cost-benefit analysis of power generation from commercial reinforced concrete solar chimney power plant, Energy Convers Manage 79 (2014) 104-113.

[9] X. Zhao, Y. Zeng, D. Zhao, Distributed solar photovoltaics in China: Policies and economic performance, Energy 88 (2015) 572-583.

[10] E. Sermyagina, J. Jussi Saari, J. Kaikko, E. Vakkilainen, Integration of torrefaction and CHP plant: operational and economic analysis, Appl Energy 183 (2016) 88-99.

[11] P. Guo, Y. Zhai, X. Xu, J. Li, Assessment of levelized cost of electricity for a 10-MW solar chimney power plant in Yinchuan China, Energy Convers Manage 152 (2017) 176-185.

[12] E. Nyholm, J. Goop, M. Odenberger, F. Johnsson, Solar photovoltaic-battery systems in Swedish households - self-consumption and self-sufficiency, Appl Energy 161 (2016) 148-159.

[13] D.U. Hung, Z.D. Dong, H. Trinh, Determining the size of PHEV charging stations powered by commercial grid-integrated PV systems considering reactive power support, Appl Energy 183 (2016) 160-169.

[14] E. Du, N. Zhanga, B.M. Hodgeb, C. Kanga, B. Kroposkib, Q. Xia, Economic justification of concentrating solar power in high renewable energy penetrated power systems, Appl Energy 222 (2018) 649-661.

[15] S. Yang, X. Zhu, W. Guo, Cost-benefit analysis for the concentrated solar power in China, Article ID 4063691 J Electr Comput Eng 2018 (2018) https://doi.org/10. 1155/2018/4063691.

[16] IRENA. Renewable energy and jobs. Abu Dhabi: International Renewable Energy Agency; 2013. < https://www.irena.org/-/media/Files/IRENA/Agency/ Publication/2013/rejobs.pdf > [accessed on 9 May, 2018]

[17] A.M. Abdullahi, V.W. Asan, J.A. Saud, M.-S. Firdaus, M.A. Muazu, A. Ricardo, et al., Solar energy potential and benefits in the gulf cooperation council countries: a review of substantial issues, Energies 11 (2018) 372, https://doi.org/10.3390/ en11020372.

[18] REN21. Renewables 2014 Global Status Report; 2014. ISBN 978-3-9815934-2-6. < http://www.ren21.net/Portals/0/documents/Resources/GSR/2014/GSR2014 full\%20report_low\%20res.pdf > [accessed on 9 May, 2018]

[19] E. Zell, S. Gasim, S. Wilcox, S. Katamoura, T. Stoffel, H. Shibli, et al., Assessment of solar radiation resources in Saudi Arabia, Sol Energy 119 (2015) 422-438.

[20] J.A. Ruiz-Arias, J. Dudhia, C.A. Gueymard, A simple parameterization of the short-wave aerosol optical properties for surface direct and diffuse irradiances assessment in a numerical weather model, Geosci Model Dev 7 (2014) 1159-1174.

[21] F. Vignola, J. Michalsky, T. Stoffel, Solar and infrared radiation measurements, CRC Press, Boca Raton, FL, 2012394, ISBN 978-1-4398-5189-0.

[22] H. Zhang, Y. Gao, Y. Zhang, V. Terzija, Quantitative synergy assessment of regional wind-solar energy resources based on MERRA reanalysis data, Appl Energy 216 (2018) 172-182

[23] A.A. Prasad, R.A. Taylor, M. Kay, Assessment of solar and wind resource synergy in Australia, Appl Energy 190 (2017) 354-367.

[24] M.M. Rienecker, M.J. Suarez, R. Gelaro, R. Todling, J. Bacmeister, E. Liu, et al., MERRA: NASA's modern-era retrospective analysis for research and applications, J Clim 24 (2011) 3624-3648, https://doi.org/10.1175/JCLI-D-11-00015.1.

[25] J.S. Bojanowski, A. Vrieling, A.K. Skidmore, A comparison of data sources for creating a long-term time series of daily gridded solar radiation for Europe, Sol Energy 99 (2014) 152-171.

[26] R. Urraca, A. Gracia Amillo, T. Huld, F.J. Martinez-de Pison, J. Trentmann, A. Lindfors, et al., Quality control of solar radiation data with satellite-based products, Sol Energy 158 (2017) 49-62.

[27] R. Urraca, A. Gracia Amillo, E. Koubli, T. Huld, J. Trentmann, A. Riihelä, et al., Extensive validation of CM SAF surface radiation products over Europe, Remote Sens Environ 199 (2017) 171-186.

[28] Y. Yi, J. Kimball, L. Jones, R. Reichle, K. McDonald, Evaluation of MERRA land surface estimates in preparation for the soil moisture active passive mission, J Clim 24 (2011) 3797-3816.

[29] G. Alexandri, A. Georgoulias, C. Meleti, D. Balis, K. Kourtidis, A. Sanchez-Lorenzo, et al., A high resolution satellite view of surface solar radiation over the climatically sensitive region of Eastern Mediterranean, Atmos Res 188 (2017) 107-121.

[30] R. Urraca, E. Martinez-de Pison, A. Sanz-Garcia, J. Antonanzas, F. Antonanzas-Torres, Estimation methods for global solar radiation: case study evaluation of different approaches in central Spain, Renew Sustain Energy Rev 77 (2017) 1098-1113.

[31] A. Boilley, L. Wald, Comparison between meteorological re-analyses from ERAInterim and MERRA and measurements of daily solar irradiation at surface, Renew Energy 75 (2015) 135-143.

[32] L. Ramírez, J.M. Vindel, Forecasting and nowcasting of DNI for concentrating solar thermal systems, Adv Concentr Sol Therm Res Technol (2017) 293-310, https:// doi.org/10.1016/B978-0-08-100516-3.00013-7.

[33] B. Jahani, B. Mohammadi, A comparison between the application of empirical and ANN methods for estimation of daily global solar radiation in Iran, Theoret Appl Climatol (2018) 1-13, https://doi.org/10.1007/s00704-018-2666-3.

[34] R. Urraca, T. Huld, A. Gracia Amillo, F.J. Martinez-de-Pison, F. Kasper, A. Sanz-Garcia, Evaluation of global horizontal irradiance estimates from ERA5 and COSMO-REA6 reanalyses using ground and satellite-based data, Sol Energy 164 (2018) 339-354.

[35] C.W. Frank, W. Sabrina, J.D. Keller, B. Pospichal, A. Hense, S. Crewell, Bias correc tion of a novel European reanalysis data set for solar energy applications, Sol Energy 164 (2018) 12-24.

[36] C. Bollmeyer, J. Keller, C. Ohlwein, S. Wahl, S. Crewell, P. Friederichs, et al., Towards a high-resolution regional reanalysis for the European CORDEX system, Quart J Roy Meteorol Soc 141 (2015) 1-15.
[37] R.S. Chen, K. Ersi, J.P. Yang, S.H. Lu, W.Z. Zhao, Validation of five global radiation models with measured daily data in China, Energy Convers Manage 45 (2004) 1759-1769, https://doi.org/10.1016/j.enconman.2003.09.019.

[38] V. Lara Fanego, Jose Ruiz-Arias, D. Pozo-Vazquez, F. Santos-Alamillos, J. Pescador, Evaluation of the WRF model solar irradiance forecasts in Andalusia (southern Spain), Sol Energy 86 (2012) https://doi.org/10.1016/j.solener.2011.02.014.

[39] L. Tiriolo, R.C. Torcasio, S. Montesanti, S. Federico, Verification of a real time weather forecasting system in southern Italy, Adv Meteorol 2015 (2015) 758250 , https://doi.org/10.1155/2015/758250.

[40] E. Avolio, R.C. Torcasio, T. Lo Feudo, R.C. Calidonna, D. Continil, S. Federico, Improvement of Solar and Wind forecasting in southern Italy through a multi-mode approach: preliminary results, Adv Sci Res 13 (2016) 69-73.

[41] J.-Y. Kim, Y. Chang-Yeol, K. Chang, Y. Kang, H. Kim, S. Lee, et al., Evaluation of WRF model-derived direct irradiance for solar thermal resource assessment over South Korea, AIP Conf Proc 1850 (2017) 140013, https://doi.org/10.1063/1. 4984521.

[42] P.A. Jiménez, et al., WRF-Solar: description and clear-sky assessment of an augmented NWP model for solar power prediction, Bull Amer Meteor Soc 97 (2016) 1249-1264.

[43] S. AlYahya, M.A. Irfan, Analysis from the new solar radiation Atlas for Saud Arabia, Sol Energy 130 (2016) 116-127.

[44] S.S. Rashwan, A.M. Shaaban, F. Al-Suliman, A comparative study of a small-scale solar PV power plant in Saudi Arabia, Renew Sustain Energy Rev 80 (2017) 313-318.

[45] B.W. Kariuki, T. Sato, Interannual and spatial variability of solar radiation energy potential in Kenya using Meteosat satellite, Renew Energy 116 (2017) 88-96.

[46] C. Hoyer-Klick, L. Wald, L. Menard, P. Blanc, E. Wey, M. Suri, et al., Solar atlas for the Southern and Eastern Mediterranean, In: 30th ISES Biennial Solar World Congress 2011, SWC 2011, vol. 5, 2011, pp. 3755-3761.

[47] Y. Eissa, M. Chiesa, H. Ghedira, Assessment and recalibration of the Heliosat-2 method in global horizontal irradiance modeling over the desert environment of the UAE, Sol Energy 86 (2012) 1816-1825.

[48] M.H. Alobaidi, P.R. Marpu, T.B.M.J. Ouarda, H. Ghedira, Mapping of the solar irradiance in the UAE using advanced artificial neural network ensemble, IEEE J Sel Top Appl Earth Observ Remote Sens (2014) https://doi.org/10.1109/JSTARS. 2014.2331255

[49] Skamarock WC, et al. A description of the Advanced Research WRF version 3 NCAR Tech. Note NCAR/TN-475+STR; 2008. p. 113. https://doi.org/10.5065/ D68S4MVH.

[50] S.L. Haupt, et al., Building the Sun4Cast system: improvements in solar power forecasting, Bull Amer Meteor Soc 99 (1) (2018) 121-135.

[51] J.A. Ruiz-Arias, H. Alsamanra, J. Tovar-Pescador, D. Pozo-Vázquez, Proposal of a regressive model for the hourly diffuse solar radiation under all sky conditions, En ergy Convers Manage 51 (2010) 881-893.

[52] Y. Xie, M. Sengupta, J. Dudhia, A Fast All-Sky Radiation Model for Solar Applications (FARMS): algorithm and performance evaluation, Sol Energy 135 (2016) 435-445, https://doi.org/10.1016/j.solener.2016.06.003.

[53] G. Thompson, T. Eidhammer, A study of aerosol impacts on clouds and precipitation development in a large winter cyclone, J Atmos Sci 71 (2014) 3636-3658, https://doi.org/10.1175/JAS-D-13-0305.1.

[54] A. Deng, N.L. Seaman, J.S. Kain, A shallow-convection parameterization for mesoscale models. Part I: submodel description and preliminary applications, J Atmos Sci 60 (2003) 34-56.

[55] Deng A, Gaudet B, Dudhia J, Alapaty K. Implementation and evaluation of a new shallow convection scheme in WRF. In: 26th Conf on Weather Analysis and Forecasting, Atlanta, GA, Amer. Meteor Soc, 12.5; 2014. < https://ams.confex.com/ ams/94Annual/webprogram/Paper236925.html >

[56] M.J. Iacono, J.S. Delamere, E.J. Mlawer, M.W. Shephard, S.A. Clough, W.D Collins, Radiative forcing by long-lived greenhouse gases: Calculations with the AER radiative transfer models, J Geophys Res 113 (2008) D13103, https://doi. org/10.1029/2008JD009944.

[57] G. Thompson, M. Tewari, K. Ikeda, S. Tessendorf, C. Weeks, J. Otkin, et al., Explicitly-coupled cloud physics and radiation parameterizations and subsequent evaluation in WRF high-resolution convective forecasts, Atmos Res 168 (2015) 92-104, https://doi.org/10.1016/j.atmosres.2015.09.005.

[58] S. Twomey, Pollution and the planetary albedo, Atmos Environ 8 (1974) 1251-1256.

[59] B. Albrecht, Aerosols, cloud microphysics, and fractional cloudiness, Science 245 (1989) 1227-1230, https://doi.org/10.1126/science.245.4923.1227.

[60] J.A. Ruiz-Arias, J. Dudhia, F.J. Santos-Alamillos, D. Pozo-Vázquez, Surface clear-sky shortwave radiative closure intercomparisons in the Weather Research and Forecasting model, J Geophys Res Atmos 118 (2013) 9901-9913.

[61] J.A. Ruiz-Arias, C.A. Gueymard, F.J. Santos-Alamillos, D. Pozo-Vázquez, Do spaceborne aerosol observations limit the accuracy of modeled surface solar irradiance?, Geophys Res Lett 42 (2015) 605-612.

[62] R. Jones, J. Murphy, M. Noguer, Simulation of climate change over Europe using a nested regional-climate model. I: assessment of control climate, including sensitivity to location of lateral boundaries, Quart J Roy Meteor Soc 121 (1995) 1413-1449.

[63] F. Feser, B. Rockel, H. von Storch, J. Winterfeldt, M. Zahn, Regional climate models add value to global model data: a review and selected examples, Bull Am Meteorol Soc 92 (2011) 1181-1192. 
[64] A. Di Luca, R. de Elia, R. Laprise, Potential for added value in precipitation simulated by high resolution nested Regional Climate Models and observations, Clim Dyn 38 (2012) 1229-1247, https://doi.org/10.1007/s00382-011-1068-3.

[65] M. Stefanon, P. Drobinski, F. D'Andrea, C. Lebeaupin-Brossier, S. Bastin, Soil moisture temperature feedbacks at meso-scale during summer heat waves over Western Europe, Clim Dyn (2013) https://doi.org/10.1007/s00382-013-1794-9.

[66] H.E. Beck, L.A. Bruijnzeel, A.I.J.M. van Dijk, T.R. McVicar, F.N. Scatena, J. Schellekens, The impact of forest regeneration on streamflow in 12 meso-scale humid tropical catchments, Hydrol Earth Syst Sci 17 (7) (2013) 2613-2635.

[67] Y. Xue, Z. Janjic, J. Dudhia, R. Vasic, F. De Sales, A review on regional dynamical downscaling in intraseasonal to seasonal simulation/prediction and major factors that affect downscaling ability, Atmos Res 147-148 (2014) 68-85.

[68] D.P. Dee, et al., The ERA-Interim reanalysis: configuration and performance of the data assimilation system, Q J R Meteorol Soc 137 (656) (2011) 553-597.

[69] Y. Viswanadhapalli, H. Dasari, S. Langodan, V.S. Challa, I. Hoteit, Climatic feature of the Red Sea from a regional assimilative model, Int J Climatol 37 (5) (2016) 2563-2581.

[70] S. Langodan, L. Cavaleri, Y. Viswanadhapalli, I. Hoteit, The Red Sea: a natural laboratory for wind and wave modeling, J Phys Oceanogr 44 (2014) 3139-3159.

[71] S. Langodan, Y. Viswanadhapalli, H.P. Dasari, O. Knio, I. Hoteit, A high-resolution assessment of wind and wave energy potentials in the Red Sea, Appl Energy 181 (2016) 244-255.

[72] Y.Z. Alharthi, M.K. Siddiki, G.M. Chaudhry, Resource assessment and techno-economic analysis of a grid-connected solar PV-wind hybrid system for different locations in Saudi Arabia, Sustainability 10 (2018) 3690, https://doi.org/10.3390/ su10103690.

[73] T. Cebecauer, M. Suri, Typical Meteorological Year data: SolarGIS approach, Energy Proc 69 (2015) 1958-1969.

[74] A.H. Murphy, R.L. Winkler, A general framework for forecast verification, Mon Weather Rev 115 (7) (1987) 1330-1338.

[75] C.J. Willmott, On the validation of models, Phys Geogr 2 (1981) 184-194.

[76] R. Attada, H. Dasari, A. Parekh, J.S. Chowdary, S. Langodan, O. Knio, et al., The role of the Indian summer monsoon variability on arabian peninsula summer climate, Clim Dyn (2018) 1-16, https://doi.org/10.1007/s00382-018-4333-x.

[77] R. Kumchala, R. Attada, H. Dasari, V. Ramesh Kumar, S. Langodan, Y. Abualnaja, et al., Aerosol Optical Depth Variability over the Arabian Peninsula using satellite and ground based observations, Atmos Environ 187 (2018) 346-357.
[78] R. Attada, H. Dasari, J.S. Chowdary, Y. Ramesh Kumar, O. Knio, I. Hoteit, Surface air temperature variability over the arabian peninsula and its links to circulation patterns, Int J Climatol (2018) https://doi.org/10.1002/joc.5821.

[79] R. Attada, K. Ravi Kumar, Y. Ramesh Kumar, H. Dasari, O. Knio, I. Hoteit, Prominent modes of summer surface air temperature variability and associated circulation anomalies over the Arabian Peninsula, Atmosph Sci Lett (2018) https://doi. org/10.1002/asl.860.

[80] H. Dasari, S. Langodan, Y. Viswanadhapalli, V.B. Rao, V.P. Papadopoulos, I. Hoteit, ENSO influence on the Red Sea Convergence Zone and Associated Rainfall, Int J Climatol (2017) https://doi.org/10.1002/joc.5208.

[81] P. Jish Prakash, G. Stenchikov, W. Tao, T. Yapici, B. Warsama, J.P. Engelbrecht, Arabian Red Sea coastal soils as potential mineral dust sources, Atmos Chem Phys 16 (2016) 11991-12004.

[82] A.A. Prasad, R.A. Taylor, M. Kay, Assessment of direct normal irradiance and cloud connections using satellite data over Australia, Appl Energy 143 (2015) 301-311.

[83] I. Elliston, A. MacGill, M. Kay Prasad, Spatio-temporal characterisation of extended low direct normal irradiance events over Australia using satellite derived solar radiation data, Renew Energy 74 (2015) 633-639.

[84] F. Crespi, A. Toscani, P. Zani, D. Sánchez, G. Manzolini, Effect of passing clouds on the dynamic performance of a CSP tower receiver with molten salt heat storage, Appl Energy 221 (2018) 224-235.

[85] N. Tindale, P. Pease, Aerosols over the Arabian Sea: atmospheric transport pathways and concentrations of dust and sea salt, Deep Sea Res Part II 46 (8-9) (1999) 1577-1596.

[86] B.H. Alharbi, The March 2009 dust event in Saudi Arabia: precursor and supportive environment, Bull Am Meteorol Soc 94 (2013) 4.

[87] A. Awad, A. Mashat, The synoptic patterns associated with spring widespread dusty days in central and eastern Saudi Arabia, Atmosphere 5 (4) (2014) 889-913, https://doi.org/10.3390/atmos5040889.

[88] C. Wei-Dong, C. Fang, Z. Hai, D. Huang, L. Deng-Xuan, Impacts of different radiation schemes on the prediction of solar radiation and photovoltaic power, Atmos Oceanic Sci Lett 10 (6) (2017) 446-451. 